\title{
A LINGUAGEM E O SIGNIFICADO DE LUGAR NA AMÉRICA LATINA
}

\author{
David J. Robinson ${ }^{1}$
}

\begin{abstract}
RESUMO: Estuda a importância cultural do conceito de lugar e sua diversificação ao longo da história. Desde o perfodo pré-conquista, entre aztecas e incas, entre os quais lugar era indicativo de parentesco, de um conjunto de relaçóes sociais com uma conotação geográfica. Nas sociedades andinas as duas partes inferior e superior do espaço social indicavam atividades complementares. Os cais designados como capellas eram santuários, correspondendo a rituais de fertilidade e colheita. A representação cartográfica dos Maias evidenciava a imagem quadripartida do universo andino (p. 79). A conquista espanhola modificaria sensivelmente os critérios de espaço; missóes, pueblos, reduciones passariam a designar uma hierarquia de poderes. $O$ autor chama atençấo para a diversidade dos critérios de designação de lugar no correr da história (p. 84) da construção do Estado nacional, com as conotaçóes locais, regionais, federalistas, centralizadoras (p. 88-93). Na época pós-moderna, por sua vez, a emergência de novos localismos de resistência contra o planejamento burocrático, com novas escalas de valores (o periférico e o metropolitano), e, finalmente, uma nova geografia do insólito a partir do turismo contem porâneo (p. 99).
\end{abstract}

UNITERMOS: localismos, geografia, simbólico, espaço, cultura.

\section{Introdução}

Para latino-americanos, que partilham a cultura da região, que conhecem pelo menos as particularidades de alguns de seus lugares, minha tentativa de generalização sobre o lugar dentro do vasto continente pode parecer tanto arrogante quanto superficial. Em minha defesa, eu posso apenas dizer que as observações, interpretaçóes e opiniões que seguem provém de mais de duas décadas examinando a variedade de paisagens latino-americanas, falando com 
ROBINSON, David. A linguagem e o significado de lugar na América Latina.

uma larga gama de pessoas, vivendo numa diversidade de lugares por diversos tempos e lendo bastante sobre lugares e acontecimentos.

Neste sentido, o que eu espero poder fazer é nada mais que exemplificar a variedade de processos concernentes ao que temos talvez concordado em chamar de "lugar" dentro da América Latina. Tentarei demonstrar o poder do lugar não pelo recurso de argumentos teóricos, mas pela evidência persuasiva do comportamento social culturalmente mediado em contextos geográficos específicos ${ }^{2}$. Serão enfatizados tanto os padrões de comportamento quanto seus contextos físicos, assim como os fatores vitais de escala de periodicidade temporal. Argumentarei que o lugar é sinergista: ele é criado e cria; lugar é construído, destruído e transformado por indivíduos e/ou grupos corporativos de nível mais alto dentro de contextos culturais específicos ${ }^{3}$. Notar-se-á, eu espero, que eu possuo uma incômoda pecepção de que, através do tempo, o significado de lugar pode ter variado mas, como a própria cultura, ter sido transformado de tal maneira a poder ser útil como um termo geral para debate. Assim como uma redução em relações interpessoais íntimas pode ser um dos custos da formação de sociedade complexas, assim também os limites restritos de pequenos lugares tem sido geralmente o de dar passagem a entidades geográficas maiores, mais notadamente a região, o Estado-nação e o império. É talvez fácil demais romantizar o pequeno (e simples) como belo para caracterizar o grande (e complexo) como desumano e feio e ainda esquecer que o mundo moderno em que vivemos (e de cujo ponto de vista podemos confortavelmente oferecer crítica reflexiva) é êle mesmo a vitória sobre as restrições impostas por um certo tipo de lugar ${ }^{4}$. O que argumentarei é que em cada período histórico tem havido vantagens e desvantagens de várias escalas de comportamento; se o lugar é significativo para a identidade social, como eu penso que sempre é, então veremos que assim como as identidades tem sido formadas ou modificadas, também os lugares tem que mudar, de privados para públicos, de vales estreitos para regiões vastas, de informais para formais, de comunidade para sociedade mais ampla - e tudo isto normalmente sob controle de uma elite, que estabelece os parâmetros das mudanças sócio-econômicas, políticas, e daí geográficas.

2 WHITE, S.. Movements in the Cultural Landscape of Highland Peru. Tese de Doutoramento. University of Wisconsin, Madison, 1981.

3 ROBINSON, David J.. From Colonial Space to Place. In: D.J. Robinson (ed.), Social Fabric and Spatial Structure in Colonial Latin America. Ann Arbor: Univ. of Michigan Press, p. 22-24, 1979.

4 SACK, R.D.. Conceptions of Space in Social Thought. London: Macmillan, 1980; SACK, R.D.. Human Territoriality. Cambridge: Cambridge Univ. Press, 1986; TUAN, Yi Fu. Topophilia. Nova Iorque: Prentice Hall, 1974; TUAN, Yi Fu. Place: An Experiential Perspective. Geographical Review, v. 65, p. 151-156, 1975. 
Minha evidência será extraída de vários séculos que testemunharam mudanças significativas no lugar latino-americano e eu saltarei com ousada impunidade do Caribe para Araucania em minha busca de dados. Tentarei invocar e interpretar o lugar de tantas perspectivas e com tantos significados quantos possíveis no espaço percebido ${ }^{5}$.

\section{A linguagem de lugar}

A palavra e o conceito de "lugar: no título deste ensaio levantaria problemas para aqueles que desejariam traduzi-lo para as principais línguas da América Latina. No caso do espanhol (e os equivalentes portugueses são muito semelhantes) é evidente que uma variedade de têrmos alternativos nos confunde (ver Quadro 1), cada um com nuanças significativamente diferentes de sentido. Em verdade, vale a pena notar, como Margaret Mead fez com relação ao filandês, que muitas vezes somente quando temos de trabalhar com uma língua diferente da nossa é que os significados cultural e temporalmente específicos atribuídos aos têrmos se nos tornam aparentes ${ }^{6}$. Embora a maioria dos têrmos no Quadro 1 derivem de raizes latinas, a evolução de seus significados, primeiro dentro da Espanha e depois no Novo Mundo, deu a cada um um sentido distinto. Embora em muitas partes da América Latina sitio veio a significar nada mais do que o lugar como um sítio, era usado em Cuba após o século 16 para descrever lugares rurais trabalhados pela agricultura ${ }^{7}$.

\section{QUADRO 1. ALGUNS TERMOS DE LUGAR EM ESPANHOL}

\section{Lugar}

lugar, sítio, situación

localidad, local, terreno

tierra, parte, paraje

término, andurrial, ámbito

ambiente, país, región

terreno,plaza.

\author{
Lugar povoado \\ pueblo, pago \\ población, poblado \\ comarca, nación \\ país, territorio \\ patria, ciudad \\ barrio, distrito.
}

ROBINSON, David J.. Cultural and Historical Perspective in Areas Studies: The Case of Latin America. In: R.U. Cooke and J.H. Johnson (eds.). Trends in Geography. London: Pergamon, 1969.

6 MEAD, W.R.. The Language of Place. Geographical Studies, v. 1, p. 63-68, 1954.

7 FRIEDERICI, G.. Amerikanistischer Worterbuch und Hilfsworterbuch für den Amerikanisten. Hamburg: Cram, de Gruyter, 1960. 
ROBINSON, David. A linguagem e o significado de lugar na América Latina.

Lugar tem sido também usado por séculos não apenas no sentido geográfico mas também no sentido alternativo em inglês de lugar na ordem hierárquica; estar fora do lugar exprime-se por fuera de lugar. Ainda para ao descrever alguém como lugareño dá-se uma conotação imediata de rusticidade (ou do sítio, em português). Podemos ainda notar a ocorrência de país (país) e patria (terra nativa ou pátria), ambas das quais tornadas importantes ingredientes na identificação do status nacional depois da virada do século 19. País também fornece a raiz da palavra que os hispano-americanos usam par denotar a paisagem (paisaje). Em espanhol paisaje, possui talvez uma maior relação com o campo aberto (com sinônimos tais como vista e panorama), do que o têrmo "landscape" da forma como ele evoluiu em inglês.

Se alguém deseja falar de lugar como um área socialmente definida ao qual as pessoas tem um sentimento de ligação, então em espanhol o contexto do lugar a ser definido é de capital importância; residentes de uma grande metrópole falariam de seu barrio, ou vecindad (bairro), mas se fossem recém-chegados a cidade eles ainda lembrariam sua tierra, patria chica, ou pueblo. Classes sociais parecem também possuir visões distintas de lugar. Reina demonstrou elegantemente que o significado de plaza, aquele lugar central mais importante nas cidades hispano-americanas, varia com a intensidade de seu uso pela gente decente e pelas classes mais baixas ${ }^{8}$. Existe também evidência a mostrar que para comunidades que estão no processo de formação a unidade política de pequena escala (distrito) pode servir como um identificador temporário de lugar. Infelizmente poucos estudos tem sido feitos até a presente data para identificar os passos-chave no processo temporal pelos quais os residentes urbanos criam ou se tornam ligados aos lugares e então articulam esta ligação ao lugar por meio de reconhecimento do lugar ${ }^{9}$. E isto ocorre a despeito de dezenas de análises de favelas e outros lugares urbanos ${ }^{10}$. O que é claro, contudo, é que a densidade variada de teias econômicas, as complexidades de associações relacionais, sejam de confiança mutua (confianza), de parentesco e apadrinhamento, ou das muitas formas pelas quais os indivíduos se integram na sociedade, todas falam de modo

8 REINA, R.. Paraná: Social Boundaries in an Argentine City. Austin: Univ. of Texas Press, 1973.

9 SANTOS, Milton. Espaço \& método. São Paulo, 1985.

10 UZZELL, D.. The interaction of population and locality in the development of squatter settlemenis in Lima. Latin American Urban Research, v. 4, p. 113-134, 1974. 
de ação que são mobilizadas quando a ocasião ou a utilidade exige ${ }^{11}$. É por essa razăo que nossa definição de lugar deve permanecer flexível, pelo menos na América Latina, pois as contingências de ação social podem requerer o que Leeds ${ }^{12}$ chamou de respostas locais ou supra-locais.

Um fato é claro: um termo genérico para o lugar como se tornou usual em nossas discussões em inglês parece ser singularmente ausente dos vocabulários espanhol e português dos séculos 16 ao 20 .

Ainda mais desafiante é qualquer tentativa de compreender os têrmos da língua ameríndia para denotar lugar. Em Quechua, dos limites ao norte em seu uso no Equador dos presentes dias para suas extensões ao sul dentro de Santiago del Estero, Argentina, existe o termo llacta (ou llactay em sua forma possessiva) que significa "terra de", "meu país", ou "meu solo"13.

Êste é provavelmente o sinônimo mais próximo que pode ser encontrado para representar o que estamos chamando de lugar. Em muitas línguas aborígenes tais como nahuatl, quiché, aymara, e ixil, faz-se uso extensivo de sufixos locativos para anexar significado especial para lugares geográficos específicos ${ }^{14}$. Por exemplo em nahuatl os sufixos -co e -tlan representam o que em portugês se expressaria por "nas proximidades de". Têrmos genéricos para lugar são notavelmente ausentes, o que em si pode indicar que localismo é tão difundido dentro da cultura, que falar de lugar genérico é tão desnecessário quanto impensável ${ }^{15}$. Devemos lembrar que o nosso "lugar" é um conceito cultural cujas origens, evolução e uso, mesmo dentro dos limites das disciplinas acadêmicas, só muito recentemente começaram a ser examinados com algum detalhe ${ }^{16}$.

11 OLIVER-SMITH, A.. The Martyred City: Death and Rebirth in the Andes. Albuquerque: Univ. of Mexico Press, 1986; ALTAMIRANO, T.. Presencia andina en Lima metropolitana: estudio sobre migrantes y clubes de provincianos. Lima: Pontifica Universidad Católica, 1984; KEMPER, R.. Migration and Adaptation: Tzintzuntzán peasants in Mexico City. Beverly Hills: Sage, 1977.

12 LEEDS, A.. Locality Power in Relation to Supralocal Power Institutions. In: A. Southall (ed.). Urban Anthropology: Cross Cultural Studies of Urbanization. New York: Oxford Univ. Press, 1973, p. 15-41.

13 LIRA, J. A.. Diccionario Kkechuwa-Español. Tucumán: Univ. Nacional de Tucumán, 1944.

14 LOCKHART, J.. Capital and Province, Spaniard and Indian: the example of late-sixteenth century Toluca. In: I. Altman and J. Lockhart, (eds.). Provinces of Early mexico. Los Angeles: Univ. of California, 1976.

15 KARRTTUNEN, F.. An Analytical Dictionary of Nahuatl. Austin, 1983.

16 BUTTIMER, A., SEAMON. The Experience of Space and Place. London: Croom Helm, 1980; TUAN, Yi Fu. Space and Place: The Perspective of Experience. Minneapolis, 1977; TUAN, Yi Fu. In Place, Out of Place. Geoscience and Man, v. 24, p. 3-10, 1984. RALPH, E. C... Place and Placelessness. London: Pion, 1976. 
Existe ainda outro meio pelo qual podemos avaliar o poder do lugar através de sua linguagem na América Latina e esse é através do "palimpsest" dos nomes de lugares. Análise toponímica, embora ainda em infância relativa na América Latina, quando comparada com a Europa, forneceu algumas das melhores evidências até agora do significado de lugar(es) diferenciado(s) no Novo Mundo ${ }^{17}$. Para o México, Toscano Moreno demonstrou que os padrões em mudança dos lugares de fazendas (estancias) desde o século 16 ao $19^{18}$; para a Nova Espanha central durante a conquista é agora claro que o que se tornou pagos (pequenas províncias) para o espanhol fora por muito tempo itocayocanes e que as menores jurisdições civis espanholas foram retiradas do nahua altepettl ${ }^{19}$. O que nos permite compreender a análise de nomes de lugares é tanto a profundidade temporal dos lugares socialmente definidos quanto a penetração dos elementos do novo nome. $\mathrm{O}$ espanhol adotou e rapidamente difundiu a partir da ilha caribenha de espanhola "sabana", um indicador de lugar de origem arawak; o têrmo quechua para um lugar gramado plano (pampa ou bamba) foi da mesma forma incluido no léxico do colonialismo e posteriormente se tornou a designação de uma região da Argentina (e Brasil) de longa influência quechua ${ }^{20}$. Topônimos gentílicos da mesma forma contam histórias complexas de conflito cultural e difusão de localidades para regiōes e em alguns casos para níveis imperiais. Como se pode explicar a súbita epidemia de nomes de lugares de origem tlaxcalan no norte do México sem entender as políticas coloniais aztecas do século 15? Ou os nomes de lugares germânicos do sul do Chile, Brasil e Paraguai sem o conhecimento das correntes migratórias do século 19? Onde quer que os colonizadores e conquistadores tenham ido, normalmente levaram seus nomes distintivos consigo e isto nos permite reconstruir tanto a cronologia quanto a geografia da mudança cultural ${ }^{21}$. Devemos atentar para o conselho de

17 RAYMOND, J.. The Indian Mind in Mexican Toponyms. América Indigena, v. XII, p. 205-216, 1952; DYKERHOFF, U.. Mexican Toponyms as a Source in Regional Ethnohistory. In: H.R. Harris and Ethnohistory, Albuquerque: Univ. Press, 1984, p. 229-252.

18 MORENO TOSCANO, A.. Toponimia y análisis histórico. Historia Mexicana, v. XIX, p. 1-10, 1969.

19 LOCKHART, J.. Some Nahua Concepts in Postconquest Guise, History of European Ideas, v. 6, p. 465-482, 1985.

20 FRIEDERICI, G.. Ob. cit.

21 HOLMER, N. M.. Indian placenames in South America and the Antilles. Names, v. 8, p. 133-149, 1960; WE1BEL, L... Place names as an aid to the reconstruction of the original vegetation of Cuba. Geographical Review, v. 3.3. p. 376-396, 1948. 
R. Histórka, São Paulo, n. 121, p. 67-110, ago/dez. 1989.

Todorov de que a denominação é muitas vezes o primeiro passo para tomar posse ${ }^{22}$.

Nomes possuem certamente, como os lugares, contéudo tanto simbólico quanto puramente descritivo. Assim quando os regimes caem, impérios entram em colapso ou uma elite local substitui outra, muito frequentemente se inicia um processo de mudança de nomes em determinados lugares. Na América Latina, uma verdadeira geografia histórica nacional pode ser lida a partir de nomes de ruas de suas cidades ${ }^{23}$.

Devemos também lembrar que qualquer que tenha sido a ilha onde Colombo primeiro aportou no Caribe ${ }^{24}$, ele teve o cuidado de denominar a seqüência dos primeiros lugares recém-descobertos numa ordem hierárquica que nos diz muito do contexto de seu empreendimento histórico: o Salvador (San Salvador); a Virgem Maria (Santa Maria de la Concepcion); o rei (Fernandina); a rainha (Isabela); e finalmente o principe real (Juana) ${ }^{25}$. Os próprios nomes das jurisdições civis - Nova Granada, Nova Galícia, Rio da Prata, Pequena Veneza - todos falam da transferência simbólica de sentimento e imaginação das esperanças coloniais.

A linguagem de lugar na América Latina assim constantemente nos permite interpretar não somente as imagens mentais e comportamento de vários grupos culturais, mas também nos fornece um instrumental valioso para compreender melhor muitos dos artefatos físicos, que inundam a paisagem com tanta profusão. Demais a mais, nossos estudos toponímicos latino-americanos são poucos, nossos dicionários etimológicos (especialmente em línguas nativas) ainda modestos em comparação com outras áreas culturais e parece haver pouco interesse ou especialização na análise de nomes. Se, como arguiria eu, não podem existir lugares sem nomes, então talvez alguém se voltará breve para o que pode ser uma das mais importantes pistas de pesquisas ainda a ser explorada?

22 TODOROV, T.. The Conquest of America: The Question of the Other. New York, 1982.

23 REINA, R.. Ob. cit, p. 67.

24 JUDGE, J., J. L. STANFIELD, The Island of Landfall. National Geographic Magazine. v. 170 , p. $566-599,1986$.

25 TODOROV, T.. Ob. cit, p. 27. 
ROBINSON, David. A linguagem e o significado de lugar na América Latina.

\section{Lugares em mudança na América Latina}

Nossa próxima tarefa será examinar uma pequena e seleta porção da evidência que demonstra o significado em mudança do lugar dentro da evolução cultural da América Latina durante suas quatro principais fases: pré-hispânica, colonial, republicana e moderna. Cada uma nos fornecerá ilustrações da extensão em que as relaçôes sociais e culturais criaram, usaram e valorizaram o lugar e como a complexidade cultural pode ser examinada através do uso contrastante do lugar.

Nawpaq pachakunapi: lugares de povos pré-hispânicos

Seria provavelmente difícil encontrar na América Latina uma relação mais próxima entre natureza e cultura e comportamento e lugar, do que pode ser encontrado no período pré-hispânico, embora ainda inadequadamente analisado. Onde quer que se olhe, as famílias aborígenes, comunidades e mesmo os proto-estados e impérios, parecem não apenas ter visualizado o lugar como parte integrante de sua cultura, mas também ter experimentado grande dificuldade em distinguir entre povo, lugar, atividades sociais e espaço. Se tomamos como exemplo as duas mais elevadas culturas presentes no Novo Mundo em contato com o homem hispânico (os aztecas e os incas), deixando de lado literalmente as centenas de outros grupos humanos, vemos que as unidades básicas de sua sociedade foram chamadas calpulli e ayllu, respectivamente ${ }^{26}$. Ambos os têrmos podem ser melhor traduzidos para o português como "territórios de parentesco", que é uma combinação de relaçōes sociais (com ênfase particular em linhagem

26 CARRASCO, P.. The Civil-Religious Hierarchy in Mesoamerican Communities Pre-Spanish Background and Colonial Development. American Antiquity, v. 63, 1961, p. 483-497; CARRASCO, P.. La casa y hacienda de un señor Halhuica. Estudios de Cultura Nahuaatl, v. X, p. 225-24, 1972; LEON-PORTILHO, M.. Mesoamerica before 1519. In: L. Halhuica. Estudios de Cultura of Latin America. Cambridge: Cambridge Univ. Press, v. 1, 1984, p. 3-36; MURRA, J.. Andean Societies before 1532. In: L. Bethell (ed.). Cambridge History of Latin America. Cambridge: Cambridge Univ. Press, v. 1, 1984 , p. $59-90$. 
e ascendência) dentro de um domínio espacial. Estes foram, de fato, lugares de povos; ou inversamente, povos de lugar. Regras de participação dentro desses artefatos socio-espaciais, particularmente articulados através de parentesco e casamento, parecem ter sido de grande significação para limitar seu tamanho geográfico. Entretanto, uma outra de suas características foi a ênfase interna de relações harmônicas: bilateralismo e complementaridade estavam embutidas em sua estrutura. Na Mesoamerica, as unidades calpulli frequentemente se gabavam de seus deuses (muitas vezes a dualidade de sexo, ou de forças contrapostas em outros lugares). Nas sociedades andinas, a partes duais de hatum e hurin (as seções de cima e de baixo do espaço social) igualmente significavam poder partilhado e atividades complementares.

Se examinamos a crua representação cartográfica de um tipo ideal de vila andina, podemos interpretar estes padrões talvez com melhor clareza (Figura $1)^{27}$. O ayllu propriamente dito é dividido em duas partes com a vila bipartite limitando suas fronteiras. A vila mesmo separa entre o fundo alto do puna (o sallqa) e o chăo do vale (o mayopatan). Irradiando do centro das duas parte saem linhas de capelas, cada uma contendo um ídolo primitivo (agora uma cruz), localizando-se as mais significantes nos limites das zonas cultural-ecológicas. Estes sítios de capela/santuário tornam-se lugares temporários de rituais de fertilidade e colheita dentro do ciclo sazonal da comunidade.

Ecologicamente o ayllu combina tanto o pasto de terra alta e solo de arar a pé, uma integração vertical conservacionista e eficiente, que Murra datou do século $15^{28}$ e que demarca socialmente o lugar dos "homens selvagens" (sallqaruna) do alto puna, dos seus contrapartes aculturados no fundo do vale. A base de poder deste lugar ayllu normalmente reside na vila, onde os varayoq (dirigentes da burocracia) mantém controle e mediam disputas numa base de rodísio, que impede um único indivíduo ou grupo de tomar o poder permanentemente. Servir como um líder andino é, desta forma, fazer um sacrifício econômico dramático e de curto prazo pelos benefícios do prestígio e de um lugar permanente na fábrica social da comunidade. Nós paramos mais altos do puna moram as divindades (os Wamanis) para quem devem ser feitos pagamentos rituais, quando a terra estiver "aberta" para tais oferendas.

27 ISABELL, B. J.. To Defend Ourselves: Ecology and Ritual in an Andean Village. Austin: Texas Univ. Press, 1978.

28 MURRA, J.. Formaciones económicas y políticas del mundo andino. Lima: IEP, 1975. 
Nosso lugar microcósmico andino, portanto, reflete uma sincronização de uso de recurso, uma mediação de conflito social por meio de hierarquias duais de prestígio, uma paisagem de nomes que quase desafia a listagem senão o mapeamento de centenas de lugares identificados no chão ${ }^{29}$. Sagrado e profano ainda possuem aqui um significado cultural que a maioria de europeus acha difícil de descrever, mas reconhece ter sido ingredientes integrais, tanto dos ayllu como dos calpulli.

Contudo, alguns naturalmente já estarão perguntando como estes microcosmos se relacionam uns com os outros e qual foi o potencial para mais largos desenvolvimentos. Para responder parcialmente a essa questão, podem voltar a evidência das estruturas imperiais incas, vistas através dos olhos perceptivos e da pena hábil de um escritor do século 17, que se alega descendente de um dos últimos incas ${ }^{30}$. Huaman Poma de Ayala nos fornece uma das mais detalhadas imagens do poder do lugar para a cultura inca em geral. Um exame cuidadoso de seu mapa-mundi (Figura 2 ) revela que, apesar de sua imitação de forma européia, seu conteúdo é rico em simbolismo de lugar. Seu estabelecimento central (onde se esperaria encontrar Jerusalém ou Roma depois de um século de mando espanhol) e Cusco, o pivô andino de quatro quartos. Em verdade, se clarificamos os detalhes das linhas indistintas em seu mapa, podemos distinguir os quatro quartos pelo nome: os quatro suyos. $O$ todo é nada mais que a representação simbólica de Tawantinsuyo, uma imagem quadripartite do universo andino.

Detalhes mais interessantes podem agora ser identificados. Os próprios quatro quartos podem ser vistos divididos em dois pares, dois formando o setor superior e dois o inferior: o modelo de império e universo podem ser vistos como contendo o mesmo hana/hurin, que notamos anteriormente no ayllu. Este é o ordenamento de lugares e espaços que Zuidema e outros identificaram como uma estrutura básica na cultura andina, tão antiga quanto nossa evidência nos permite enxergar $^{31}$. Outros etno-historiadores argumentam que superior e à direita

29 PLATT, T.. Symétries en miroir. Le concept de Yanantín chez les Marcha de Bolivies. Annales, E.S.C.. v. 33, p. 1101-1112, 1978.

30 ADORNO, R.. Guaman Poma: Writing and Resistence in Colonial Peru. Austin: Univ. of Texas Press, 1986; PEASE, F. (ed.). Nueva Crónica y Buen Gobierno de Felipe Guamán, Poma de Ayala, Caracas: Biblioteca Ayacucho, 1985.

31 ZUIDEMA, R. T.. The ceque System of Cusco: The Social Organization of the Capital of the Incas. Leiden: E. J. Brill, 1964; HARRISON, R.. Modes of Discourse: the Relación de Antiguedades deste reyno del Perú, by Joan Salcamaygua. In: R. Adorno (ed.). From Oral to Written Expression: Native Andean Chronicles of the Early Colonial Period. Syracuse: FACS, 1982; LÓPEZ-BARALT, M.. La persistencia de las estructuras simbólicas andinas en los dibujos de Guamán Poma de Avala. Jornal of Latin American Lore, v. 5, p. 83-116, 1979. 
đireita podem ser equacionados com masculinidade e que se contrapõem com a complementariedade do feminino (inferior/à esquerda). A não ser que se pense que a representação de Huaman Poma nada mais é do que uma construção teórica, deveria mencionar-se que arqueólogos estāo achando quantidades crescentes de informação, que demonstram ter sido os limites dos quatro suyos (as linhas "ceque"), não apenas frequentemente demarcados no chão, mas também a estruturação da sociedade local ter sido afetada por sua presença.

Graças à recente análise etno-histórica, também sabemos muito mais sobre o significado dos quatro quartos nas relações de poder entre os vários grupos competidores. Ganhar acesso ao lugar mais central (Cusco) era o objetivo de todos os que disputavam autoridade entre os incas. A partir dos templos na grande praça de lados abertos em Cusco, debaixo da barriga do puma simbólico, que dava a forma da própria cidade, de entre as pernas matafóricas dos deuses, um vasto impérío podia ser encontrado ${ }^{32}$.

Qualquer tentativa para resumir os elementos do mundo pré-hispânico deveria necessariamente salientar não apenas a interdependência da forma cultural, do comportamento social e do lugar, mas também a maneira pela qual os lugares pequenos e grandes estavam dispostos hierarquicamente e, talvez mais importante para nossas preocupações imediatas, alocados em paralelo nas posições de poder retidas pela elite inca. Ser removido para Quito ou o Chile central era a pior fatalidade que um oficial do império poderia esperar.

Igualmente importante era a maneira como no período imediatamente anterior ao contato hispânico, estas macro-estruturas sofriam pressão e tensão, quando o poder supra-local se encontrava desafiado tanto a partir de sua própria sociedade, crescentemente segmentada e hierarquizada, como por desafios externos de grupos não-sedentários ${ }^{33}$.

\section{Pondo o colonialismo no lugar}

Nosso segundo estágio, o de colonialismo hispânico, nos fornece uma rica diversidade de comportamento em ação agora num estágio bastante deliberado:

32 CHÁvez BALLón, M.. Ciudades Incas: Cuzco, capital del imperio Wayka, v. 3, p. $1-14,1970$.

33 STERN, S.. Peru's Indian Peoples and the Challenge of Spanish Conquest: Huamanga to 1640. Madison: Univof Wisconsin Press, 1982; SPALDING, K.. Huarochirl: An Andean Society under Inca and Spanish Rule. Stanford: Stanford Univ. Press, 1984. 
ROBINSON, David. A linguagem e o significado de lugar na América Latina.

o de poderes imperiais inclinados a estabelecer sua própria identidade cultural. Em muitas instâncias, isso podia ser melhor levado a cabo por meio de políticas estabelecidas para minar e derrubar a base de poder das culturas aborígenes, assim como um processo persistente de reestruturação cultural ${ }^{34}$. No âmago da segunda alternativa, reside um novo conjunto de regras e regulamentos de lugar, com que tanto Espanha quanto Portugal (em menor extensão) tentaram obrigar a população indígena a seguir. $O$ povo aborígine (pelo menos o que não morreu de morte acidental por epidemia) tinha que ser firmemente posto em seu lugar: e este lugar era decididamente sob controle político branco, nas sombras profundas da segregação racial e com separação física dos recém-chegados ${ }^{35}$.

Os hispânicos trouxeram consigo para o Novo Mundo um conjunto de instituições, um complexo de artefatos culturais e padrões de comportamento, que imediatamente os distinguiu de seus antecedentes. A fé católica, a família ampliada, o sistema urbano, o desejo e o gozo conspícuo de riqueza material tudo isso teve sérias conseqüências para a construção de lugares e mudanças de lugares na América Latina.

Talvez os mais simbólicos dos novos lugares criados na América espanhola foram os muito lugares urbanos, que foram estabelecidos ao longo do império em rápida expansão. O sistema de ruas em xadrez, o lugar central (a Plaza), as diferenciações formais e funcionais entre central e periférico, tudo denotava uma nova ordem cultural ${ }^{36}$. O mais humilde dos estabelecimentos, alguns dos quais dificilmente seriam designados como urbanos, incluiam esses elementos vitais. No seu centro localizava-se a plaza, o espaço aberto, onde se colocavam os símbolos gémeos do poder imperial espanhol, a espada e a cruz, que era para funcionar por séculos como o lugar onde socializar-se, através de reunióes públicas, ou a cerimônia de cortejamento do paseo; o lugar onde conduzir negócios, seja através da instalação de mercados (e feiras) ou pelo

34 WACHTEL, N.. Pensée sauvage et acculturation. L'espace et le temps chez Felipe Guamán Poma de Ayala. Annales. E.S.C, v. 41, p. 793-840, 1971.

35 LOCKHART, J., SCHWARTZ, S.B.. Early Latin America. Cambridge, Cambridge Univ. Press, 1983.

36 NUTTALL, Z.. Royal Ordinances Concerning the Laying Out of New Towns. Hispanic American Historical Review, v. 4, p. 743-753, 1921 e v. 5, p. 249-254, 1922; BORAH, W.. European Cultural Influences in the Foundation of the First Plan for Urban Centers that have Lasted to our Time. In: R.P. Schaedel et al. (eds.). Urbanización y proceso social en América Latina. Lima: IEP, 1972. 
cercamento de arcadas cobertas; o lugar para comportar-se na maneira correta de um vecino, um residente orgulhoso e registrado da cidade ${ }^{37}$.

Em torno da plaza situavam as representações físicas do poder imperial: a igreja, o conselho municipal, o escritório do vice-rei, etc. Frequentemente esses edifícios apresentavam sua significação para a sociedade em geral não apenas pela sua localização, mas também pela sua construção elaboradamente decorada de dois andares, muitas vezes nada mais que fachadas, que escondiam a realidade mais mundana do aspecto da cidade. O repicar do sino e o troar dos canhóes lembravam as pessoas sobre o campanilismo dos antecedentes mediterraneos, onde pertencer ao estabelecimento significava ficar a um tiro de espingarda ${ }^{38}$.

Esses lugares urbanos não eram legalmente destinados para uso residencial pelos índios: para proteger os últimos de uma possível contaminação cultural com os vícios dos hispânicos, forneciam-se-lhes estabelecimentos a discreta distância da cidade dos brancos. Os pueblos indígenas replicavam a forma das cidades hispânicas e funções similares, porém mais restritas, do que as da gente decente de origem hispânica ${ }^{39}$.

Este "civilizar por colonização" promoveu as maiores campanhas a fim de realocar a população indígena dispersa. O obje tivo maior em reestabelecê-los em vilas nucleizadas (as famosas congregaciones ou reduciones) era permitir melhor controle político e administrativo e facilitar a requerida conversão dos pagãos a nova fé católica ${ }^{40}$. É importante notar que a descida da serra pela população aborígene, além de representar uma nova fase colonial na agricultura em terras aráveis do fundo do vale, também significava um distanciamento por parte deles de seus deuses da montanha. É evidente também que nas novas vilas, estruturas de duas partes recriadas eram fatalmente penetradas pelo lugar central intruso, $o$ que desequilibrava a dualidade dos lugares aborígenes.

37 BOBERTSON, D.. A Behavioural Portrait of the Mexican Plaza Principal. Tese de Doutoramento, Syracuse University, 1978; GADE, D. W.. The Latin American Central Plaza as a Functional Space. In: R.J. Tata (ed.). Latin America: Search for Geographic Explanations. Boca Raton, 1974, p. 16-234; TAKAGI, H.. The Plaza and its functions in a Mexican highland community: Tepeojuma. Geographical Review of Japan, v. 43, p. 22-31, 1970.

38 PITT-RIVERS, J. A.. The People of the Sierra. Chicago: Univ of Chicago Press, 1961. 39 GIBSON, C. The Aztecs under Spanish Rule. Stanford: Stanford Univ. Press, 1964.

40 FALS BORDA, O.. Indian Congregations in the New Kingdom of Granada. The Americas, v. 13, p. 331-351, 1956-57; C.LINE, H. F.. Civil Congregation of the Indians in New Spain, 1598-1606. Hispanic American Historical Review, v. 29, p. 349-369, 1949; MALAGA MEDINA, A.. Las reducciones en el virreinato del Peru (1532-1580). Revista de Historia de América, v. 80, p. 9-45, 1975; LOVELL, W. G.. Conquest and Survival in Colonial Guatemala. Kingston: Queen's McGrill Univ. Press, 1985. 
Onde quer que condições dificultassem o controle civil, um conjunto de novos lugares eram estabelecidos - as missões de ordem regulares ${ }^{41}$. Centenas de igrejas abandonadas e em ruinas, algumas recentemente restauradas como monumentos nacionais, inundam a paisagem da América Latina contemporânea.

Dentro desses lugares urbanos coloniais, os primeiros focos de poder imperial, pode-se ainda reconhecer uma outra escala de fabricação de lugar: o de casa e lar. A micro-ecologia da cidade colonial refletia as normas culturais dos intrusos hispânicos. A branca periferia de paredes altas da casa colonial demarcava o mundo reservado, que se situava além dos sons e (normalmente mal) cheiro da cidade. No melhor dos casos, o acesso a esses lugares privados era através de um portão de entrada obrigatório, que falava do status e prestígio de seu proprietário. Os poucos afortunados poderiam mesmo gabar-se de um brazão para combinar com seu título de "Don". Passando pelo corredor, situavam os pátios designados, que forneciam em ordem hierárquica um foco de atividades diferenciadas racial e funcionalmente. Quanto mais o visitante se afastava da porta da frente, o mais se aproximava das dependências dos servos e escravos ${ }^{42}$.

Gostaria de sugerir um paralelo simbólico e funcional entre os lugares de escala urbana (arco cerimonial, vias processionais, plazas) e aqueles das unidades residenciais (portão de entrada, passagens, pátios). Tanto na arena pública quanto na privada, era-se informado sobre o adequado comportamento, vestuário, linguagem, e assim por diante, pela posição relativa em que uma pessoa era colocada ${ }^{43}$.

Em ocasiões especiais, os códigos sociais e relações de poder dentro das colônias eram suspensos temporariamente em inversóes de rituais, que permitiam aos humildes parodiar os poderosos, aos pobres ridicularizar os ricos, aos pretos

41 RICARD, R.. La conquête spirituelle du Méxique. Essai sur l'apostolat et les méthodes missionaires des Ordres Mendiants en Nouvelle Espagne, de 1523 a 1572. Paris, 1933; SPECKER, J.. Die Missionmethode in Spanisch-Amerika im 16 Jahrhundert. Cologne: Schoneck-Beckenried, 1953; ROBINSON, David J.. The Syndicate System of the Catalan Capuchins of Colonial Southeast Venezuela. Revista de Historia de América, v. 79, p. 63-76, 1975.

42 ROBINSON, David, J.. Córdoba en 1779: ciudad y campana. Gaea, v. 17, p. 279-312, 19796 GASPARINI, G.. La casa colonial Venezolana. Caracas, 1962; GUARDA, G.. Historia urbana del reino de Chile. Santiago, 1978; TORRE REVELLO, J.. La casa y el mobilario en Buenos Aires colonial. Revista de la Universidad de Buenos Aires, v. 3, p. 285-300, 1945.

43 HOBERMAN, L. S.. Conclusion. In: L. S. Hobreman and S. M. Socolow (eds.). Cities and Societies in Colonial Latin America. Albuquerque: Univ. of New Mexico Press, 1986; ROBINSON, David J.. La ciudad colonial hispanoamericana: símbolo o texto?. In: José Luis Peset (ed.). Actas del simposio internacional: La ciencia en España e Iberoamérica. Madrid, 1988. 
e índios literalmente usar as máscaras dos brancos e todos gozarem a liberdade fugaz da igualdade assistida sem rubor, devido à ingestão de grande quantidade de aguardente. Por meio de festas públicas e carnavais, o povo podia, de certa forma, mudar os lugares sociais. Fornecia um excelente meio de reduzir as muitas tensões sociais.

As procissões públicas e os arranjos de sentar na igreja e nas armações erguidas na plaza também forneciam ocasiões, não apenas para expor a posição social, onde o poder era demonstrado pela proximidade da pessoa junto ao altar ou da imagem carregada, mas também provocava brigas, que podiam resultar em ações judiciais. Os têrmos "preeminencia de asiento" (privilégio de sentar) e "orden del desfile" (ordem hierárquica da procissão), invocados em muitos casos legais, falavam claramente de uma sociedade, que ligava grande valor ao lugar ${ }^{44}$. A morte também era outra oportunidade para o descendente de alguém rememorar seu lugar na sociedade através de uma solene tumba, apropriada e bem situada. Os mausoléus e nichos dos cemitérios latino-americanos falam eloquentemente desta modalidade de privilégio póstumo ${ }^{45}$.

Entretanto, devemos lembrar que o tipos ideais de cidade hispanica e aldeia indígena raramente sobreviveram, de maneira alguma intatas até o século 17. Mistura racial, desenvolvimento econômico e migração populacional brevemente parecem ter ofuscado as agudas divisões teóricas entre os lugares distintos. Em redor e frequentemente dentro das cidades, cresceram os setores indígenas (barrios), muitas vezes providos de suas próprias facilidades paroquiais. Alguns membros da elite logo perceberam que existiam lucros a serem auferidos ao alugar porções de suas casas centralmente localizadas a artesãos e comerciantes ${ }^{46}$.

Os residentes da cidade eram também elementos numa teia espacial mais ampla de interêsses econômicos, de obrigações sociais e poder político por força de conexões de família. Se ser uma pessoa "de bem" era ser alguém de um lugar

44 COLOMBIA, Archivo Nacional de Colombia. Sección Policía, v. X, fls. 537-703. "José Peinado y José Antonio Piedrahita, Alferez Real y Teniente prreminencia de asiento en las ceremonias públicas", 1796.

45 REINA, R.. Paraná: Social Boundaries in an Argentine City. Austin: Univ. of Texas Press, 1973.

46 GÓNGORA, M.. Urban Social Stratification in Colonial Chile. Hispanic American Historical Review, v. 55, p. 421-448, 1975; RAMOS, D.. Vila Rica: Profile of a Colonial Brazilian Urban Center. The Americas, v. 35, p. 495-526, 1979; MORENO TOSCANO, A. ed.. Ciudad de México: Ensayo de Construcción de una Historia. Mexico: INAH, 1978. 
conhecido e de ascendência distinta, então muito mais importantes eram pessoas que tinham acesso a recursos dentro de uma maior amplitude geográfica. No século 18, as famílias notáveis da América Latina podiam gabar-se de suas redes de ligações, que iam desde minas a fazendas, de propriedades com escravos a residências urbanas, dos mosteiros à côrte imperial. A completa significação de regiões como complexos de famílias expandidas, interrelacionadas somente agora se torna mais evidente ${ }^{47}$.

Entretanto, o que sabemos da identidade dos lugares dentro e fora destas cidades que evoluiram? A resposta infelizmente é relativamente diminuta. Está claro que os bairros recebem nomes, enquanto o tempo progride, mas até o presente é difícil assegurar o papel dos residentes neste processo ${ }^{48}$. É evidente que dentro de duas gerações de residência, os hispânicos começam a falar com orgulho exagerado de sua recém-criada patria chica de base urbana. Rivalidade interurbana/regional, talvez um indicador úlil de identidade, já no século 18 tinha atingido proporções, que começavam a alarmar as côrtes imperiais. E existe outra medida pela qual podemos estimar o significado do lugar para colonizadores tanto urbanos quanto rurais. Podemos ver nos termos usados para descrever migrantes, tanto temporários quanto permanentes, que aos olhos hispânicos não pertenciam a nenhum lugar fixo (os vagos, vagabundos, huidos), indicando a ameaça que representavam para a estabilidade da ordem social ${ }^{49}$. Se uma pessoa não era conhecida numa localidade, năo pertencia a um lugar, como se poderia julgar sua etnicidade, sua moralidade e seu valor para a comunidade? Transeuntes, fossem artesãos à procura de trabalho, índios em fuga da taxação rigorosa, ou a sempre dúbia e crescente classe mestiça - todos eram suspeitos. Em verdade, a legislação era frequentemente, embora sem sucesso, mobilizada para devolver essa pessoas a seus devidos lugares ${ }^{50}$.

Talvez a maior medida de ligação ao lugar na América Latina colonial é proporcionada por aqueles, que perderam o privilégio de morar lá. É nos angustiosos lamentos dos jesuítas exilados do século 18, que podemos

47 BALMORI, D. et al.. Notable Family Networks in Latin America. Chicago: University of Chicago Press, 1984; KICZA, J.. Colonial Entrepreneurs: Families and Business in Bourbon Mexico City. Albuquerque: Univ of New Mexico Press, 1983; KUZNESOF, E., OPPENHEIMER, R. (eds.). The Latin American Family in the Nineteenth Century, Special issue on Family History. v. 10, 1985.

48 BORAH, W.. Trends in recent Studies of Colonial Latin American Cities. Hispanic American Historical Reveiw, v. 64, p. 535-554, 1984.

49 ROBINSON, David J.. (ed.). Population Migration in Colonial Latin America. Cambridge, 1989.

50 FARRISS, N. M.. Nucleation versus dispersal: the dynamics of population movement in colonial Yucatan., Hispanic American Historical Review, v. 58, p. 187-216, 1978. 
estabelecer a primeira identidade de amplitude continental com a América Latina como um lugar. Talvez esta americanização ou creolização fosse uma conseqüência do que Lynch descreveu como a segunda conquista da América? ${ }^{51}$ Somente quando os "criolos" (nascidos na América) aprenderam rapidamente a odiar os advindos peninsulares (os gachupines e chapetones) que tinham chegado com as reformas dos Bourbons, começou a emergir uma apreciação de seu lugar próprio - a América. A convicçāo de que americanos nāo eram espanhóis, porém venezuelanos, mexicanos, chilenos e peruanos, pôde somente emergir como resultado dos longos séculos de desenvolvimento colonial. Ao fazer seus próprios lugares, ao criar sua própria identidade, os hispânicos tiveram finalmente que rejeitar suas origens no Velho Mundo.

Os jesuítas criolos exilados tornaram-se os precursores literários do nacionalismo americano, e foi uma literatura de nostalgia, numa medida nada desprezível. Manuel Lacunza "imaginava-se comendo seus pratos chilenos favoritos, enquanto Juan Ignacio Molina sentia sede das águas da cordilheira. $\mathrm{O}$ mexicano Juan Luis Maneiro implorava ao rei espanhol, que lhe permitisse morrer 'em solo pátrio'" 52 .

Já que a precondição para o amor de seu próprio lugar (patriotismo) era o conhecimento, os panfletos e jornais da última parte do século 18 floreceram com fatos novos da geografia, dos recursos e do potencial desta nova terra prometida. Exibia-se um americanismo sem inibiçôes; "a pátria", "nossa nação", "nossa América", "nós os americanos" ${ }^{53}$. Podemos compreender a preocupação das autoridades imperiais: 0 amor pelos lugares americanos parecia ter erodido perigosamente a obediência política. Breve muitos americanos seriam chamados a pagar o último preço por seu patriotismo.

51 LYNCH, J.. The Spanish American Revolutions, 1808-1826. New York: W.W. Norton, 1973.

52 GONZÁLEZ, L.. El optimismo nacionalista como factor de la independencia de México. Estudios de Historiografia Americana, v. 12, p. 158, 1948.

53 VIAL CORREA, G.. "La formación de nacionalidades hispano-americanas como causa de la independencia. Boletín de la Academia Chilena de Historia, v. 333, p. 110-144, 1966; GRAVALES G.. Nacionalismo incipiente en los historiadores coloniales. México, 1961; BURRUS, E.J.. Jesuit Exiles, Precursors of Mexican Independence?. Mid-America, v. 36, p. 161-175, 1974. 
ROBINSON, David. A linguagem e o significado de lugar na América Latina.

\section{Revolução e republicanismo: lugares novos e velhos}

Se a luta para terminar o colonialismo mostrou-se difícil para os latino-americanos, não menos árdua foi sua busca por um conjunto de novas identidades ${ }^{54}$. Era mais fácil libertar-se da Espanha e Portugal, do que tornar-se brasileiros, argentinos, e guatemaltecos ${ }^{55}$. O desafio era agora forjar novas alianças sócio-políticas, incutir dentro da população liberada um carinho por e um orgulho de seu novo lugar conquistado no mundo. E como em quase todas as circunstancias similares, a questão mais difícil era decidir exatamente quanto rejeitar do velho e quanto proporcionar do novo. A tarefa de examinar o lugar dentro da América Latina tornou-se muito mais difícil já que cada uma das novas nações republicanas abordava esta questão central de maneira distinta. Esperamos aqui nada mais que ilustrar tendências ou processos que se difundiram através do continente. Devemos também ressaltar que a velocidade e a direção da mudança quase nunca foram sincronizadas.

Tornar-se Estado primeiro exigia a repressão de rivalidades regionais ${ }^{56}$. Os autores desta nova estrutura macro-regional e artífices de controle político e administrativo baseado em modelos da Europa ocidental rapidamente se lançaram a manipular e mediar a ordem regional segundo os supostos interesses dos desavisados cidadãos das novas repúbicas. Na Argentina de Rosas o estado policial em breve estava usando mazorcas para "limpar" a nova república, servindo os laxativos de pimenta vermelha com as mesmas finalidades do óleo de castor usado posteriormente pelos fascistas italianos 57 .

Em toda parte e simultaneamente um único lugar capital começava agora a estabelecer-se a parte do resto; um sítio costeiro era normalmente um sine qua non já que o comércio e as conexões internacionais padronizavam cada vez mais

54 LAFAYE, J.. Quetzalcoatl and Guadalupe; The Formation of Mexican National Conciousness, 1531-1815. Chicago, 1976.

55 HAWKINS, J.. Inverse Images: The Meaning of Culture, Ethnicity and Family in Postcolonial Guatemala. Albuquerque, 1984; GOSSEN, G. H.. Chamulas in the World of the Sun: Time and Space in a Maya Oral Tradition. Cambridge, 1974; STABB, M. S.. In Quest of Identity: Paterns in the Spanish American Essay of Ideas, 1890-1960. Chapel Hill, 1967.

56 SECKINGER, R.. The Brazilian Monarchy and the South American Republics, 1822-1831: Diplomacy and State Building. Baton Rouge, 1984.

57 ARCiNIEGAS, G.. Civilization and Barbarism. In: Latin America: A Cultural History. New York, 1966, p. 351-377; LYNC.H, J.. Argentine Dictator: Juan Manuel de Rosas, 1829.1852. Oxford, 1981. 
sobre a nova vida "nacional". Os litorâneos agora confrontavam os interioranos, e várias periferias coloniais atingiram posições centrais ${ }^{58}$. Tanto nos estados-nações unitários quanto federativos, o centro dominante começava vagarosamente mas seguramente a cobrar tributos de suas dependências internas regionais. Para aqueles situados no lugar central de regalias renovadas, a ilusão nacional era promovida e reforçada por símbolos de centralidade e coesão: o Palácio Nacional, o Tesouro Nacional, leis e mapas nacionais. Entretanto, é claro que sob muitos aspectos tal "nacionalismo" era pouco mais que um mito. Exatamente como a nova elite adotava novas posições, ideologias, e políticas a fim de assegurar sua própria estabilidade, assim também seus Estados permaneceram pouco mais que imagens vistas de cima ou de fora até os regimes autoritários do final do século 19 e início do século 20 , quando os fracos aparelhos de estados foram fortalecidos e a população foi informada sobre seu lugar e como comportar-se ${ }^{59}$. No México, o ditador Porfírio Díaz podia referir-se a seus legisladores como ao "meu rebanho de cavalos mansos" ${ }^{60}$. A educação de massa tornou-se não apenas um meio de modernização, mas também um instrumento necessário de endoutrinação nacional ${ }^{61}$. Se o Estado precisava de fronteiras bem definidas (o uti possidetis tinha-se provado um tanto obscuro), assim os cidadãos também precisam de um hino e uma bandeira. $O$ reconhecimento como um Estado forte frequentemente requeria um inimigo comum e os vizinhos serviam bem a este propósito ${ }^{62}$. O continentalismo cultural (panamericanismo) brevemente se forjou a partir das rivalidades de competição pelos lugares de liderança na nova ordem econômica e política ${ }^{63}$.

58 SCOOBIE, J. R.. Revolution on the Pampas: A Social History of Argentine Wheat. Austin, 1964; HUMPHREYS, R. A.. The Caudillo Tradition. In: M. Howard (ed.). Soldiers and Governments. London, 1957, p. 149-165; EIDT, R. C... Pioneer Settlement in Northeast Argentina. Madison, 1971.

59 BRADING, D. A.. Los origenes del nacionalismo mexicano. México, 1973.

60 SIMPSON, L. B.. Many Mexicos. Berkeley, 1952.

61 PIKE, F.B.. Spanish America, 1900-1970: Tradition and Social Innovation. London, 1973; C:AMPOS HARRIET, F.. Desarrollo educacional, 1810-1960. Santiago, Chile, 1960; WOLL, A.. A functional past. The uses of history in nineteeth century Chile. Baton Rouge, 1982; SPALDING, H. A.. Education in Argentina, 1890-1914: the limits of oligarchical reform. Journal of Interdisciplinary History, v. 3, p. 41-53, 1972.

62 CLISSOLDS., HENNESSY A.. Territorial Disputes. In: C.. Veliz (ed.). Latin American and the Caribbean. London, p. 403-412, 1968.

63 HILTON, R. (ed.). The Movement Toward Latin American Unity. New York, 1969; KARNES, T.L.. The Failure of Union: central America, 1824-1960. Chapel Hill, 1983. 
ROBINSON, David. A linguagem e o significado de lugar na América Latina.

Nas áreas urbanas, o ambiente construído foi modificado para celebrar o triunfo da independência política: boulevards e vias processionais abriam a visão para os artefatos justapostos do Estado-nação. As casas do Congresso ficavam em frente ao palácio presidencial, estando o último situado dentro de ou sobre o complexo administrativo do vice-rei. (Como no século 16, o melhor lugar para um inimigo era debaixo dos pés do seu adversário. $)^{64}$. Não muito distante ficavam os quartéis militares, que infelizmente breve aprenderam as oportunidades a eles proporcionadas como guardiães da constituição. $\mathrm{O}$ estatuário das praças refletiam os novos heróis nacionais: San Martin, Almirante Brown, Bolivar, O'Higgins, Santander.

Em vários países, a estrutura física da cidade em mudança era acompanhada por uma nova mistura étnica. Uma onda virtual de imigrantes rapidamente se concentrava seletivamente em enclaves étnicos. Colonizadores britânicos, judeus, germanicos e italianos forneciam agora identidades culturais para as novas secções da cidade ${ }^{65}$.

E cada comunidade étnica fornecia a demanda para suas necessidades tanto de recreação quanto ocupacionais. Os britânicos com seus clubes de polo e cricket; os italianos construindo lançamentos de boche; e os creolos, para não serem sobrepujados, criando o que eles imaginavam serem os passatempos apropriados para homens e mulheres decentes - passeio de barco no Regata Club no Lago Xoximilco, corrida com cachorros em Santiago do Chile ${ }^{66}$, um dia nas corridas do Jockey Club em Buenos Aires - e em todo lugar o café, o parlatório de fumantes, a sala de chá, e o discreto saláo de jogo ${ }^{67}$.

64 SCOBIE, J. R.. Buenos Aires: from Plaza to Suburb, 1870-1910. New York: Oxford Univ. Press, 1974.

65 NEWTON, R. C.. German Buenos Aires, 1900-1933: Social Change and Cultural Crisis, Austin, 1977; SOLBERG, C.. Immigration and Nationalism: Argentina and Chile, 1890-1914. Austin, 1970; SZUCHMAN, M.. The Limits of the Melting Pot in Córdoba, 1869-1909. Hispanic American Historical Review, v. 57, p. 24-50, 1977,; BAILY, S. L.. Marriage Patterns and Immigrant Assimilation in Buenos Aires, 1882-1923. Hispanic American Historical Review, v. 60, p. 32-48, 1980; WHITEFORD, S.. Workers from the North: Plantations, Bolivian labor and the C'ity in Northwest Argentina. Austin, 1981; BOURDE, G.. Urbanisation et immigration en Amérique Latine: Buenos Aires. Paris, 1974; SOPHER, E. F.. From Pale to Pampa: The Jewish Immigrant Experience in Buenos Aires. New York, 1980.

66 MAYO, J.. British Merchants and Chilean Development, 1851-1886. Westview: Boulder, 1987.

67 BOSSIO, J. A.. Los cafés de Buenos Aires. Buenos Aires, 1968; SCOBIE, J. R.. Buenos Aires as a Commercial Bureaucratic City, 1880-1910. American Historical Review. v. 77, p. 1035-1073, 1972. 
R. Histórla, Săo Paulo, n. 121, p. 67-110, ago/dez. 1989.

A velha cidade colonial passava por mudanças dramáticas. O lugar de trabalho não era mais no lar; as novas casas eram agora modeladas à moda européia e realocavam o pátio interno como uma sacada verde em torno do prédio, normalmente protegido do uso público por uma cerca de ferro forjado, importada e imposta ao visitante. Estes novos palácios falavam de riqueza e poder. Agora as pessoas se identificavam não apenas pela locação e estilo de suas residências, mas também pela linguagem que falavam (ou sotaque que usavam), sua vestimenta, comidas, bebidas e gestos; e naturalmente por suas conexões sociais ${ }^{68}$. Os lugares na América Latina urbana e republicana proliferaram rapidamente.

Nas áreas rurais, novas paisagens estavam também sendo criadas: as inovações tecnológicas da Europa e EUA permitiam cercar milhões de acres e ará-los pela primeira vez. Novas colheitas, novos trabalhadores agrícolas e novos mercados estimulavam o crescimento econômico e a identidade regional. Em outras regióes, o início da mineração do ouro, de guano de nitratos, posteriormente de cobre, estanho, ferro, e petróleo fez surgir nova riqueza que só ocasionalmente retornava para os centros urbanos; a vasta maioria de novos ricos preferia imitar os espanhóis e juntar-se a eles. Não se deve esquecer que para encontrar os verdadeiros ricos latino-americanos, pelo ano de 1900 , dever-se-ia visitar os hotéis de Londres, Paris e especialmente a Riviera Francesa.

A mineração Norte Grande foi acrescentada ao Norte Chico colonial chileno assim como a floresta ao sul colonizada pelos alemães ${ }^{69}$. A Argentina testemunhou a criação de sua nova região dos pampas e no extremo sul um estranho povo galês lutava por estabelecer seu Cwm Hafryd em Chubut ${ }^{70}$. Na Venezuela central, alemães construiram sua versão tropical da Floresta Negra e

68 CALDEIRA, T. P.. Houses of Respect, paper presented at Latin American Studies Association meeting, Boston, 1986; NEEDELL, J. D.. Rio de Janeiro at the Turn of the Century: Modernization and the Parisian Ideal , Journal of Interamerican Studies, v. 25, p. 83-103, 1983.

69 BUTLAND, G. J.. The Human Geography of Southern Chile. London, George Philip, 1957; O'BRIAN, T. F.. The Nitrate Industry and Chile's Critical Transition, 1870-1891. New York, 1982; PEDERSON, N.. Th Mining Industry of the Norte Chico, Chile. Evanston, 1966; BERNINGER, O.. Wald und öffenes Land Sud-Chile seit der Spanischen Erobung. Stuttgart, 1929; VAYSSIÈRE, P.. Un siècle de capitalisme minier au Chile, 1830-1930. Paris, 1980; BLANCPAIN, J.. Les allemands au Chili, 1816-1945. Cologne, 1974.

70 SLATTA, R. W.. Gauchos and the Vanishing Frontier. Lincoln, 1983; BOWEN, E.. The Welsh colony in Patagonia, 1865-1885: a study in historical geography. Geographical Journal, v. 132, p. 16-32, 1966. 
ROBINSON, David. A linguagem e o significado de lugar na América Latina.

na Guiana venezuelana, britânicos e trinidadenses mineraram os campos auríferos de Caratal com tanto sucesso que a Venezuela temeu por sua própria soberania $^{71}$.

No Brasil, Venezuela e Costa Rica, terras de café prosperavam e a colonização germânica procedia a passos largos ${ }^{72}$. Até a remota Amazônia sentiu a ação desenvolvimentista da borracha ${ }^{73}$, as estepes da Patagônia atrairam a atenção de colonizadores galeses e escoceses ${ }^{74}$ e os escoceses se dirigiram para os pampas ${ }^{75}$.

Todos esses novos e antigos lugares transformados, simbolizavam suas novas identidades com nomes. El Dorado, aquele lugar humano tão diligentemente procurado pelos espanhóis, tornou-se un carimbo para dezenas de empreendimentos minerais e provavelmente milhares de fazendas. Llaneros da pradarias venezuelana e colombiana ouviram do que seria sua contraparte dos pampas, os gaúchos ${ }^{76}$; os mistis e cholos peruanos agora se tornaram ayacuchanos, ancashinos, e cusqueños. Paulistas e antioqueños comparavam-se favoravelmente, aos ianques do norte por causa de seu trabalho duro e diminuiam o estilo de vida e pretensões dos cariocas e bogotanos ${ }^{77}$. Novas Chicagos, Novas Philadelphias, Novas Califórnias, Novas Providências - os novidadeiros começavam a abarrotar os registros cartográficos cuidadosamente construídos.

71 ROBINSON, David J.. Exploración de oro y su impacto en el panorama cultural de la Guayana venezolana en el siglo XIX , Boletín de la Academia de Ciencias Naturales (Caracas), v. 31, p. 61-111, 1973.

72 ROSEBERRY, W.. Coffee and Capitalism in the Venezuelan Andes. Austin, 1983; BERGQUIST, C.. Coffee and Conflict in Colombia, 1886-1910. Durham, NC, 1978; FRANCA, A.. A marcha do café e as frentes pioneras. São Paulo, 1956; HOLLOWAY, T.. Immigrants on the land. Coffee and society in São Paulo, 1886-1934. Chapel Hill, 1980.

73 WEINSTEIN, B.. The Amazon Rubber Boom, 1850-1920. Stanford, 1983.

74 REY BALMACEDA, R.. Geografia histórica de la Patagonia. Tese de Doutoramento, Universidade de Buenos Aires, 1961; WILliAMS, R. Bryn. Y Wladfa. Cardiff, 1964; WILliAMS, R. Bryn. The structure and process of Welsh emigration to Patagonia , Welsh History Review, v. 8, p. 42-74, 1976.

75 KOROL, J. C., SABATO, H.. The Camps: inmigrantes irlandeses en la provincia de Buenos Aires, 1870-1890. Buenos Aires, 1979; KOROL, J. C., SABATO, H.. Como fué la inmigración irlandesa en la Argentina. Buenos Aires, 1981.

76 RAUSCH, J. M.. A Tropical Plains Frontier: The Llanos of Colombia, 1531-1831. Albuquerque, 1984; NICHOLS, M.. The Gaucho. New York, 1968.

77 PARSONS, J. J.. Antioqueño Colonization in Western Colombia. Berkeley, 1968; MORSE, R. M.. From Community to Metropolis: a Biography of Säo Paulo. Gainsville, 1958; DEAN, W.. The Industrialization of São Paulo, 1880-1945. Austin, 1969. 
Entretanto temos ainda que recordar que a onda de imigrantes não era sempre bem-vinda. Muitos na Argentina, Chile e Venezuela os viam como cidadãos suspeitos; alguns se perguntavam de quem era realmente o país quando setores inteiros de Buenos Aires falavam alemão e inglês. $O$ anti-semitismo também levantou sua cabeça horrenda. Claramente uma política de portas abertas para imigraçăo, basicamente para responder às demandas de mão-de-obra barata, detinha sérias conseqüências potenciais. "Governar e povoar" era um provérbio do dia, mas alguns perguntavam exatamente quem estaria governando quem? $\mathrm{Na}$ virada do século, os jornais chilenos podiam falar de imigrantes como "mais sujos que os cães de Constantinopla" e "ondas da escória humana lançadas em nossa praia por outros países" ${ }^{78}$. Ramos Mejía descreveu o recém-chegado imigrante como "uma pessoa grossa, um daqueles seres de baixo nível que os futuros cientistas estudariam com curiosidade a fim de estabelecer a ligação de tipos sucessivos de nossa evolução. Com seus gostos baratos e sensuais, seu amor por cores vivas, música rouca e roupa berrante, eles são simplesmente inferiores ${ }^{\text {n }}{ }^{79}$.

Exatamente como os índios dos Andes e Mesoamérica, os novos imigrantes eram para ser usados para fins nacionalistas somente quando interessava aos homens no poder.

\section{Abrindo caminho para a modernidade}

Na longa caminhada para criar e modernizar os novos Estados havia, é certo, alguma regiōes e localidades que não gozavam senão de um mínimo progresso. Nunca existia, afinal, bastante dinheiro para ser distribuido por todos. Podia-se breve identificar o início de um novo padrão de lugar: lugares de abundância e lugares de abandono, de um novo provincialismo agora percebido como uma ligação doentia com tradições que conflitavam com as novas

78 SOLBERG, C.. Immigration and Nationalism: Argentina and Chile, 1890-1914. Austin, 1970.

79 RAMOS MEJÍA, J.M.. Las multitudes argentinas. Buenos Aires, 1899. 
ROBINSON, David. A linguagem e o significado de lugar na América Latina.

demandas do Estado ${ }^{80}$. Clivagens étnicas combinavam com províncias fisiográficas para delimitar lugares problemáticos. Os não-participantes do processo político, a despeito de que fossem proibidos por lei, ou fossem completamente ignorantes do assunto, brevemente perceberam que a resposta dos poderosos era de benigno despreso quando muito ${ }^{81}$. Quando, em certas ocasiôes, a incômoda democracia exigia votos, podia-se sempre confiar nos chefóes regionais para subornar e ameaçar o número necessário de camponeses $^{82}$. A independéncia política do começo do século 19 , finalmente conseguiu aos poucos modificar a economia agrária das ex-colônias.

Na década de 1880 , ficou claro que para progredir em qualquer coisa tinha-se que se aproximar da cidade, e para o próximo século primeiro um punhado e depois um avalanche de migrantes sacrificou as conhecidas inadequações de seu contexto rural e de pequena cidade pelas promessas da cidade grande ${ }^{83}$. Os latino-americanos do século 20 teriam forçosamente que caminhar na direção da modernidade ${ }^{84}$.

Ocasionalmente, uma epidemia de protestos rurais podia explodir, mas as possibilidades de contágio eram facilmente limitadas dada a combinação relativamente eficiente de brutalidade policial e mínimas ofertas de reforma ${ }^{85}$.

80 WIRTH, J. D.. Minas Gerais in the Brazilian Federation, 1889-1937. Stanford, 1977; LEVINE, R. M.. Pernambuco in the Brazilian Federation, 1889-1937. Stanford, 1978; LOVE, J. L.. São Paulo in the Brazilian Federation, 1889-1937. Stanford, 1980; WEINSTEIN, B.. Brazilian regionalism. Latin American Research Review, v. 17, p. 262-276, 1982; MALLON, F. E.. The Defense of Community in Peru's Central Highlands: Peasant Struggle and Capitalist Transition, 1860-1940. Princeton, 1983; MONTOYA, R.. Capitalismo y no capitalismo en el Perú: Un estudio histórico de su articulación en un eje regional. Lima: Mosca Azul, 1981; GONZÁLEZ, M. J.. Plantation Agriculture and Social Control in Northern Peru, 1875-1933. Austin, 1985.

81 SCHMITT, H. C.. The roots of lo Mexicano: self and society in Mexican thought, 1900-1934. College Station, Texas, 1969.

82 BRADING, D. A. ed.. Caudillo and Peasant in the Mexican Revolution. Cambridge, 1980.

83 HALL, M. M., SPALDING, H. A.. The urban working class and early Latin American labour movements, 1880-1930: In: L. Bethell (ed.), Cambridge History of Latin America, Cambridge, v. IV, p. 325-366, 1986; BERGQUIST, C... Labor in Latin America: Comparative Essays on Chile. Argentina, Venezuela and Colombia. Stanford, 1986.

84 GRAHAM, D. H., BUARQUE DE HOLANDA, S.. Migration, regional and urban growth and the development of Brazil. São Paulo: Instituto de Pesquisas Económicas, 1971; HAGERMAN JOHNSON, A.. Internal migration in Chile to 1921. Tese de Doutoramento. University of California at Davis, 1978; CASTELHANOS DE SJOSTRAND, M. E.. La población de Venezuela. Migraciones internas y distribución espacial, 1908-1935. Semestre Histórico, v. 1, p. 5-62, 1975; LAITE, J.. Industrial development and migrant labor in latin America, Austin, 1981.

85 BENJAMIN, T., McNELLIE, W. (eds.). Other Mexicos: Essays on Regional Mexican History, 1876-1911. Albuquerque, 1984. 
Mesmo com a onda de mudanças revolucionárias no México, que reconstruiu a paisagem agrícola de vastas áreas, não era difícil encontrar quem desejava sacrificar o potencial de mudança radical pelos menos arriscados, e certamente mais confortáveis, benefícios da conformidade. Apenas sob as circunstâncias mais provocativas e repressivas, os latino-americanos optaram por luta armada e rebeliảo aberta, freqüentemente em ligação com forças e ideologias não-locais ${ }^{86}$. Um dos custos do localismo não teria sido a inabilidade de perceber a posssibilidade de mudar o status quo do Estado, ou dos sistemas sócio-econômicos e políticos que lhe davam apoio?

Uma coisa é certa: nos últimos 20 anos, a América Latina testemunhou o ressurgimento de identidades locais e regionais, dentro dos domínios tanto urbanos quanto rurais. Em suas mudanças para a cidade, os campesinos nem romperam os laços com sua cidade natal, nem se assimilaram homogeneamente dentro de um amálgama cultural urbano. Pelo contrário, existe evidéncia disponível em quase todos os paises, para demonstrar a manutenção de laços sociais e de raízes culturais ${ }^{87}$. Os clubes regionais (e Lima em 1985 possuia uns 1850) forneceu um novo mecanismo institucional, que consolidou a propinquidade residencial como o sine qua non da a identidade comunitária. A intensidade das reuniões de fim-de-semana parecem mais que compensar a falta de contato do dia-a-dia ${ }^{88}$. O seu lugar na cidade é assim não uma zona residencial segregada, mas sim um ponto de encontro. Quem sabe o mesmo era válido também para os vales andinos?

86 WOMAC:K, J.. Zapata and the Mexican Revolution. New York, 1969; RUIZ, R. E.. Labor and the ambivalent revolutionaries: Mexico 1911-1923. Baltimore, 1976; MAYER, J.. La révolution mexicaine. Paris, 1973; JOSEPH, G. M.. Revolution from without: Yucatan Mexico and the United States, 1880-1924. Cambridge, 1982; WASSERMAN, M.. Capitalists, caciques and revolution: elite and foreign enterprise in Chihuahua, 1854-1911, Chapel Hill, 1984; COCKROFT, J. D.. Mexico: class formation, capital accumulation, and the state. New York, 1983; KATZ, F.. Peasants in the Mexican revlution of 1910. In: J. Spielberg and S. Whiteford (eds.). Forging Nations: A Comparative View of Rural Ferment and Revolt. Lansing, 1976, p. 61-85.

87 COLLIER, D.. Squatters and Oligarchs. London, 1976; DOUGHTY, P. L.. Behind the back of the city: 'Provincial' life in Lima, Peru. In: W. Mangin (ed.). Peasants in Cities. London, 1974; HIROBAYASHI, L. R.. The migrant village association in Latin America: A comparative analysis. Latin American Research Review. v. 21, p. 7-30, 1986; ROBERTS, B. R.. The interrelationship of city and province in Peru and Guatemala , Latin American Urban Research. v. 4, p. 207-235, 1974.

88 ALTAMIRANO, T.. Presencia andina en Lima metropolitana: estudio sobre migrantes y clubes de provincianos. Lima: Pontffica Universidad Católica, 1984. 
ROBINSON, David. A linguagem e o significado de lugar na América Latina.

Quando o Estado era incapaz de fornecer abrigo e serviços aos recém-chegados, eles faziam o que estavam acostumados a fazer em suas comunidades rurais - ajudar-se uns aos outros. As milhões de casas de favela, rancho e barriada, todas fabricadas sem os benefícios de engenheiros civis e arquitetos e de acabamentos em concreto com estilo, falavam eloquentemente de soluções locais para problemas locais. As faenas e turnos levaram a cabo o que nenhum Ministro da Habitação teve a capacidade ou a vontade de fazer mesmo com ajuda internacional ${ }^{89}$. Certamente, aos olhos daqueles que preferiam a elegância comprada com prestações mutuárias, os artefatos destas comunidades periféricas foram objeto de condenação, reforma ou de erradicação, a fim de serem realocados para fora da vista dos suburbanos mais afluentes 90 .

Ocasionalmente, os fundadores de cidades convocavam os assim chamados especialistas para assisti-los a lidar com os problemas cada vez maiores do crescimento das cidades. A cidade do Rio de Janeiro fornece um caso ilustrativo. Le Corbusier, que foi convidado a visitar o Rio em 1929, admitiu ter sido inspirado pela beleza pura da localização da cidade, tanto que se permitiu "um forte desejo, um pouco louco talvez, de tentar uma aventura humana $\rightarrow$, o desejo de estabelecer uma dualidade, de criar 'a afirmação do homem' contra ou com 'a presença da natureza, 91 . Essa afirmação, contudo, era, para ter tomado a forma de uma imensa auto-pista de 100 metros de altura, com conjuntos de apartamentos em baixo, que seria "um poema de geometria..." Felizmente para o Rio esse poema permaneceu no papel e ainda se pode gozar da beleza caótica de Copacabana e Ipanema.

Os políticos foram também rápidos em apreciar os benefícios potenciais de sentimentos fortemente enraizados, aos níveis local e regional ${ }^{92}$. A maioria

89 LOBO, S.. A House of My Own: Social Organization in the Squatter Settlements of Lima, Peru. Tucson, 1982; TUAN, Yi Fu. Space and Place: The Perspective of Experience. Minneapolis, 1977; PORTER, A.. Housing policy urban poverty and the state: the favelas of Rio de Janeiro, 1972-1976. Latin American Research Review, v. 14, p. 3-24, 1979; CONWAY, D., BROWN, J.. Intra-urban relocation and structure: low income migrants in Latin America and the Caribbean. Latin American Reserch Review, v. 15 , p. $95-126,1980$.

90 EPSTEIN, D. G.. Brasilia, Plan and Reality: A Study of Planned and Spontaneous Urban Development. Berkeley, 1973; HOLSTEN, J.. The Modernist City: Architecture, Politics and Society in Brasilia. Tese de Doutoramento, Yale University, 1986.

91 EVENSON, N.. Two Brazilian Capitals: Architecture and Urbanism in Rio de Janeiro and Brasilia. New Haven, 1973.

92 OSZLAK, O.. The Historical Formation of the State in Latin America: Some theoretical and Methodological Guidelines for its Study. Latin American Research Review. v. 16, p. 3-32, 1981. 
das grandes questões políticas da América Latina no século 20 podem ser vistas como originárias no contexto de alguns conjuntos específicos de circunstâncias locais ${ }^{93}$. Os habitantes das altas colinas de Quito breve colidiram com os apressados liberais de Guayaquil, que só viam benefícios numa nova ordem liberal de base comercial ${ }^{94}$.

O aprismo, embora inicialmente concebido como uma aliança pan-americana, requeria o estímulo das condições de trabalho aterradoras dos Estados plantadores de açúcar do norte do Peru e a repressão militar local a fim de construir sua base ${ }^{95}$. Somente após políticas deliberadas de difusão da mensagem do partido poderia ele posteriormente desafiar e finalmente superar os preconceitos dos militares e a maioria do eleitorado peruano. FRENATRACA, a nova liga de camponeses de Puno, está da mesma forma expandindo correntemente sua base regional ${ }^{96}$. Em cada país; as raízes das ideologias partidárias originaram-se das localidades, de individuos em contextos que exigiram reavaliações de justiça social e políticas do Estado ${ }^{97}$.

Para a esquerda ideológica, a cidade, com sua exibição flagrante de riqueza e capitalismo ianque, forneceu um alvo notável para crítica e recrutamento de apoiadores. Quando os camponeses recusaram ou não lhes foi permitido aceitar a oferta de revolução armada, os guerrilheiros e os subversivos definidos pelo Estado também se transferiram para as cidades: sandinistas, fidelistas, tupamaros, montoneros, senderistas - a lista é longa ${ }^{98}$.

93 WORTMAN, M.. Legitimidad polftica y regionalismo. El imperio Mexicano y Centroamerica. Historia Mexicana, v. 26, p. 238-262, 1976; BUSHNELL, D.. The Santander Regime in Gran Colombia. Newark, 1954; FLORES GALINDO, A.. Arequipa $y$ el Sur Andino, siglos XVIII-XX. Lima: IEP, 1977.

94 DELER, J.P.. Genèse de l'espace equatorien. Essai sur le territoire et la formation de l'état national. Paris, 1981; ALAYA, E.. Lucha politica y origen de los partidos en Ecuador. Quito, 1978.

95 KLÁREN, P. F.. Modernization, dislocation and Aprismo: origins of the Peruvian Aprista party, 1870-1932, Austin, 1973; VANDEN, H. E.. Mariátegui: Marxismo, Comunismo, and Other Bibiographical Notes. Latin American Research Review. v. 14, p. 61-86, 1979.

96 ROJAS SAMANAZ, A.. Partidos politicos en el Perú. Lima, 1985.

97 MAGALLANES, M. V.. Los partidos politicos en la revolución venezolana. Caracas, 1973; CARVALHO J. M. de, A construção da ordem. A elite política imperial. Rio de Janeiro, 1980; HARDOY, J. E., LANGDON, M. E.. El pensamiento regional en Argentina y Chile entre 1850 y 1930. Mimeo, 1982; PARK, J. W.. Rafael Nuñez and the Politics of Colombian Regionalism, 1863-1886. Baton Rouge, 1985; ANDERLE, A.. Los movimientos politicos en el Perú. Havana: Casa de las Américas, 1985.

98 KOHL, J., LITT, J.. Urban Guerrilla Warfare in Latin America. Boston, 1974; GOTT, R.. Rural Guerrillas in Latin America. London, 1970; GILLESPIE, R.. Soldiers of Peron: Argentina's Montoneros. Oxford, 1982. 
Para os muitos que desejaram mudança social mais rápida durante as últimas décadas, suas comunidades e lugares se tornaram suas tumbas: nas terras altas de Ayacucho, em Ucchurracay, em dezenas de lugares ainda não identificados, los desaparecidos fizeram o último sacrifício para suas tradições antigas e novas ${ }^{99}$.

Entretanto, além das escalas local e nacional, o lugar relativo da América Latina dentro da estrutura de poder do continente e da economia política mundial em expansão foi vagarosamente se estabelecendo. John Bull apoderou-se avidamente dos recursos no século 19 sendo seguido da atenção paternalística de Tio Sam no século 20. As "crianças" latino-americanas podiam ser mantidas felizes dentro da custódia protetora de Mr. Monroe; "irmás" erráticas podiam ser gentilmente persuadidas a comportar-se propriamente; até vizinhos enraivecidos podiam ser tolerados, embora sem muita satisfação e podia-se cuidar de uma dor de garganta reformista, ou de uma úlcera revolucionária por meio de dólares ou, quando necessário, aplicando a força ${ }^{100}$. Os latino-americanos começaram a ficar coletivamente conscientes sobre onde tinham sido colocados pelo seu vizinho mais poderoso do norte. Notaram que os "americanos" eram anglos, e não latinos, e se ressentiam profundamente do fato de serem vistos como um virtual embaraço para o progresso hemisférico. Uma vez formados os estereótipos de povos e lugares, torna-se difícil qualquer modificação.

Contudo, dentro da própria América Latina os problemas de lugar continuam. As tentativas de regionalização e a decentralização do desenvolvimento econômico frequentemente se forjaram nas rochas do regionalismo, de pessoas que não queriam seguir as recomendações de cientistas espaciais e corretores do poder ${ }^{101}$. Os sentimentos de lugar surpreenderam mais de um político ou consultor de desenvolvimento internacional. Infelizmente ainda carecemos de meios técnicos para incluir tais sentimentos no planejamento e no sistema polf́tico de decisão, tanto que os conflitos e as tensōes continuam.

99 THORNDIKE, G.. Uchuraccay: testimonia de una masacre. Lima, 1983.

100 JOHNSON, J. J.. Latin America in Caricature. Austin, 1980.

101 HARRIS, R.. Centralization and decentralization in Latin America. In: G.S. Cheema and D. A. Rondinelli (eds.). Decentralization and Development. Policy Implementation in Developing Countries. Beverly Hills, 1983; DELGADO MEDINA, C.. La critica del centralismo y la cuestión regional. Lima, 1984; WHITEHEAD, L.. National power and local power: the case of Santa Cruz de la Sierra, Bolivia., Latin America Urban Research, v. 3, p. 23-48, 1973. 
Existe, contudo, pelo menos uma direção em que o lugar e o amor pelos lugares estão fazendo avanços significativos; trata-se do desenvolvimento rápido da indústria turística que tem feito mais talvez para a preservação dos lugares que qualquer outra coisa nesses últimos 20 anos. Poucos são os países que não possuem um ministério que tenta direcionar visitantes em férias para uma variedade de lugares notáveis. $O$ insólito, o tradicional, o remoto, o exótico esses são os lugares que ganharam uma nova extensão de vida. Ainda mais quando eles possuem um folclore fotogênico com música e canções (quanto menos inteligíveis, melhor), danças, artesanatos e costumes fortes. Subitamente o mundo moderno está ansioso para visitar lugares e a América Latina é afortunada por estar bem cotada na lista de preferências ${ }^{102}$. Até o turismo interno é agora uma indústria em expansão em muitos países pois a população urbanizada está sendo persuadida a "descobrir" seu próprio país novamente. $O$ transporte moderno transformou potencialmente qualquer lugar num possível sítio ou rota.

\section{Conclusões}

Embora este artigo sobre a significação do lugar na América Latina apenas permitiu vislumbrar um assunto que demanda atenção mais detalhada, podem-se extrair algumas conclusões. Primeiro, existe a sempre presente questão de escala. Se os lugares são construções sociais, então como melhor podemos comparar, digamos, a casa ou o lar com o Estado-nação? Talvez devêssemos visualizar os mecanismos operacionais que permitem às pessoas ligar-se a lugares de tipos bem diferentes? Ao nível da unidade doméstica ou de parentesco de uma pequena vila pode ser significativo na intensidade e freqüência da interação. Porém ao nível dos sistemas de cidade somente algumas famílias podem manter laços, refugiando-se o restante da população na proliferação de instituições tais como clubes, escolas, lojas de bairro, etc? Assim talvez a ligação com o lugar não se enfraquece com a modernização mas se transforma, com disfarces novos e sutis. Uma pessoa pode pertencer a vários lugares em vez de um só; e uma pessoa pode pertencer a um desses lugares por durações diferentes de tempo.

102 BRYDEN, J. M.. Tourismo and Development. Cambridge, 1973. 
ROBINSON, David. A linguagem e o significado de lugar na América Latina.

Somente se precisa comparar as histórias de vida (ou geobiografias) de grupos distintos dentro da sociedade para ver que o "lugar potencial" de alguém aumenta grandemente na medida em que a cultura se torna mais complexa ${ }^{103}$.

Segundo, fica claro a partir do desenvolvimento Latino Americano que cada cultura possui sua própria maneira particular de usar e designar valor ao lugar. Todavia, até a cultura pode ser um conceito demais grosseiro para bem avaliar a significação de lugar. Só se tem que examinar os resultados diferenciais da criação do lugar pelas classes ricas e pobres da mesma cultura para ver que gradações sociais mais finas de análise podem ser necessárias. Igualmente importante é o tempo: dentro da mesma classe social o lugar pode ter uma significação bem distinta de um período para outro.

Terceiro, os lugares experimentais - , aqueles lugares que se conhece pessoalmente, através da sola do próprio sapato, pelo sofrimento das imtempéries, pelo amor e ódio para com as pessoas que moram lá - esses tipos de lugares eu gostaria de distinguir dos lugares de imagem -- lugares que se podem raramente visitar ou habitar, ou experimentar da mesma forma que se podia antigamente, mas lugares pelos quais uma pessoa pode estar preparada para lutar ou morrer ${ }^{104}$. Esses lugares são muito mais construções mentais no sentido em que as informações sobre as quais baseamos nossos sentimentos são bastante indiretas. Pode-se pensar sobre os comentários de um frade franciscano que, no século 16, falou sobre "As Índias", quando é improvável que ele jamais se afastou da ilha caribenha de Espanhola. Ou dos pontos de vista dos literatos argentinos sobre a selvageria no campo do século 19 quando eles raramente abandonaram o conforto de Buenos Aires ${ }^{105}$. Ou a vontade dos argentinos de mandar seus filhos para morrer por um pequeno grupo de ilhas nas águas geladas do Atlântico $\mathrm{Sul}^{106}$. Este lugar é na consciência e no sentimento diferente dos lugares onde cresceram.

Quarto, o sentido dual de lugar em inglês (lugar como localidade e como hierarquia ou ordem) encaixa-se muito bem nos padrões latino-americanos de

103 HERNANDO, D.. Casa y Familia: Spatial Biographies of Nineteenth Century Buenos Aires. Tese de Doutoramento, Univ. da California, UCLA, 1973.

104 TUAN, Yi Fu. Place: An Experimental Perspective. Geographical Review, v. 65, p. 151-156, 1975.

105 FRANCO, J.. Spanish American Literature. Cambridge, 1969.

106 GAMBA, V.. The Falklands/Malvinas War: A Model of North-South Crisis Prevention. New York, 1986; COLL, A., AREND A.. The Falkland War, lessons for Strategy, Diplomacy and Intenacional Law. New York, 1985. 
cognição de lugar. A coinciclência da centralidade espacial e da importancia social no período colonial é evidente per se. Ainda mais interessante é o fato de que os socialmente importantes (a elite) podiam mudar de lugar geográfico significativamente, e ainda manter sua posição social. Devia-se acrescentar a seus muitos atributos, a habilidade em manter prestígio enquanto troca de identidade.

Quinto, existe a persistência do lugar. Quão difícil tem sido na América Latina erradicar lugares completamente, uma vez construidos e identificados. Talvez a memória social é tão bem servida pelos artefatos da paisagem como o é por quaisquer textos escritos?

$\mathrm{E}$, finalmente, existe lugar como contexto de controle. Alguém pode escalar a pirâmide do poder no período colonial - no lado eclesiástico, do confessionário ao santuário da igreja, ao átrio, à paróquia, à sé, e finalmente à Roma. Lá alguém pode penetrar na autoridade civil, atraves do Patronato Real, e descer do Conselho das Índias através da vice-realeza e da intendéncia para corregedor e alcaide. Cada nível tem seu próprio lugar e símbolos. $\mathrm{O}$ mesmo ocorre no período moderno, quando agências governamentais planejam para os desprovidos de poder que tem de habitar novos lugares, sejam eles vilas de colonização na Amazônia ou cidades-satélites para trabalhadores de construção discretamente localizadas fora de Brasília ${ }^{107}$.

Tamanho também pode fazer diferença, pois afinal, depois de tudo, a confiança vem com a grandeza. Quem no poderoso Brasil está se preocupando com os acontecimentos nos lugares das florestas de Honduras? Ou quem no México sequer sabe onde os peruanos e argentinos estão propondo realocar suas capitais? Devemos lembrar que o que é sagrado para uns, é profano para outros - a dessacracalização e utilização de recursos são freqüentemente dois lados da moeda do desenvolvimento. Existe talvez um consolo em planejar lugares onde outros devam morar?

Uma coisa é certa, a América Latina nos fornece abundante evidência do persistente significado do lugar. O importante é para a América Latina alcançar o lugar que ela (ou coletivamente seus povos) insiste que merece tanto dentro do hemisfério quanto no mundo. Com Washington situada no centro do mapamundi contemporaneo, isto pareceria ser uma vă esperança quando muito. Todavia, os

107 LEFF, N. H.. Underdevelopment and development in Brazil. London: Allen and Unwin, 1982. 
ROBINSON, David. A linguagem e o significado de lugar na América Latina.

latino-americanos aprenderam através da experiência de séculos que a esperança do lugar futuro deve ser o apanágio de sua herança cultural.*

\section{BIBLIOGRAFIA}

ADORNO, R.. Guaman Poma: Writing and Resistence in Colonial Peru. Austin: Univ. of Texas Press, 1986.

ALAYA, E.. Lucha polttica y origen de los partidos en Ecuador. Quito, 1978. ALTAMIRANO, T.. Presencia andina en Lima metropolitana: estudio sobre migrantes y clubes de provincianos. Lima: Pontífica Universidad Católica, 1984.

ANDERLE, A.. Los movimientos polfticos en el Perú. Havana: Casa de las Américas, 1985.

ARCINIEGAS, G.. Civilization and Barbarism. In: Latin America: A Cultural History. New York, 1966, p. 351-377.

BAILY, S. L.. Marriage Patterns and Immigrant Assimilation in Buenos Aires, 1882-1923. Hispanic American Historical Review, v. 60, p. 32-48, 1980.

BAILY, S. L.. The Adjustment of Italian Immigrants in Buenos Aires and New York, 1870-1914. American Historical Review, v. 88, p. 301-325, 1983.

BALMORI, D. et al.. Notable Family Networks in Latin America. Chicago: University of Chicago Press, 1984.

BENITEZ, L.. Los Olivos. Barracas al Norte, 1895-1960. Para la antología de los barrios porteños. Buenos Aires, 1965.

BENJAMIN, T., McNELLIE, W. (eds.). Other Mexicos: Essays on Regional Mexican History, 1876-1911. Albuquerque, 1984.

BERGQUIST, C.. Coffee and Conflict in Colombia, 1886-1910. Durham, NC, 1978.

BERGQUIST, C.. Labor in Latin America: Comparative Essays on C'hile. Argentina, Venezuela and Colombia. Stanford, 1986.

- Nota: Eu agradeço minha orientanda de doutorado, Maria Celia Coelho, por sua assistência na traduçäo desse artigo do inglès para o português e por sua colaboraçäo pertinaz em localizar itens existentes ma bibliografia brasileira. 
R. História, São Paulo, n. 121, p. 67-110, ago/dez. 1989.

BERNINGER, O.. Wald und öffenes Land Sud-Chile seit der Spanischen Erobung. Stuttgart, 1929.

BLANCPAIN, J.. Les allemands au C'hili, 1816-1945. Cologne, 1974.

BORAH, W.. European Cultural Influences in the Foundation of the First Plan for Urban Centers that have Lasted to our Time. In: R.P. Schaedel et al. (eds.). Urbanización y proceso social en América Latina. Lima: IEP, 1972.

BORAH, W.. Trends in recent Studies of Colonial Latin American Cities. Hispanic American Historical Reveiw, v. 64, p. 535-554, 1984.

BOSSIO, J. A.. Los cafés de Buenos Aires. Buenos Aires, 1968.

BOURDE, G.. Urbanisation et immigration en Amérique Latine: Buenos Aires. Paris, 1974.

BOWEN, E.. The Welsh colony in Patagonia, 1865-1885: a study in historical geography. Geographical Journal, v. 132, p. 16-32, 1966.

BRADING, D. A.. Los orígenes del nacionalismo mexicano. México, 1973.

BRADING, D. A. (ed.). Caudillo and Peasant in the Mexican Revolution. Cambridge, 1980.

BRYDEN, J. M.. Tourism and Development. Cambridge, 1973.

BURRUS, E.J.. Jesuit Exils, Precursors of Mexican Independence?. Mid-America, v. 36, p. 161-175, 1954.

BUSHNELL, D.. The Santander Regime in Gran Colombia. Newark, 1954.

BUTLAND, G. J.. The Human Geography of Southern Chile. London: George Philip, 1957.

BUTTIMER, A., SEAMON. The Experience of Space and Place. London: Croom Helm, 1980.

CALDEIRA, T. P.. Houses of Respect. (Paper presented at Latin American Studies Association meeting). Boston, 1986.

CAMPOS HARRIET, F.. Desarrollo educacional, 1810-1960. Santiago, Chile, 1960.

CARRASCO, P.. The Civil-Religious Hierarchy in Mesoamerican Communities Pre-Spanish Background and Colonial Development. American Antiquity, v. 63, p. 483-497, 1961.

CARRASCO, P.. La casa y hacienda de un señor Halhuica. Estudios de Cultura Nahuaatl, v. X, p. 225-24, 1972.

CARVALHO J. M. de. A construção da ordem. A elite política imperial. Rio de Janeiro, 1980. 
ROBINSON, David. A linguagem e o significado de lugar na América Latina.

CASTELHANOS DE SJÔSTRAND, M. E.. La población de Venezuela. Migraciones internas y distribución espacial, 1908-1935. Semestre Histórico, v. 1, p. 5-62, 1975.

CHÁVEZ BALLÓN, M.. Ciudades Incas: Cusco, capital del imperio. Wayka, v. 3, p. 1-14, 1970.

CLINE, H. F.. Civil Congregation of the Indians in New Spain, 1598-1606. Hispanic American Historical Review, v. 29, p. 349-369, 1949.

CLISSOLD S., HENNESSY, A.. Territorial Disputes. In: C. Veliz (ed.). Latin American and the Caribbean. London, 1968, p. 403-412.

COCKROFT, J. D.. Mexico: class formation, capital accumulation, and the state. New York, 1983.

COLOMBIA, Archivo Nacional de Colombia. Sección Policía, v. X, fls. 537-703. "José Peinado y José Antonio Piedrahita, Alfe rez Real y Teniente prreminencia de asiento en las ceremonias públicas" , 1796.

COLL, A., AREND A.. The Falkland War, lessons for Strategy, Diplomacy and Intenacional Law. New York, 1985.

COLLIER, D.. Squatters and Oligarchs. London, 1976.

CONWAY, D., BROWN, Jr.. Intra-urban relocation and structure: low income migrants in Latin America and the Caribbean. Latin American Reserch Review, v. 15, p. 95-126, 1980.

DEAN, W.. The Industrialization of São Paulo, 1880-1945. Austin, 1969.

DELER, J-P.. Genèse de l'espace equatorien. Essai sur le territoire et la formation de l'état national. Paris, 1981.

DELGADO MEDINA, C.. La crítica del centralismo y la cuestión regional. Lima, 1984.

DEMELAS, D. Nationalisme sans nations? La Bolivie aux XIX-XX siècles. Paris.

DOUGHTY, P. L.. Behind the back of the city: Provincial life in Lima, Peru. In: W. Mangin (ed.). Peasants in Cities. London, 1974.

DYKERHOFF, U.. Mexican Toponyms as a Source in Regional Ethnohistory. In: H.R. Harris and Ethnohistory, Albuquerque: Univ. Press, p. 229-252, 1984.

EBBING, J. E.. Aimara:gramática y diccionario. La Paz: Editorial Don Bosco, 1965.

EIDT, R. C.. Pioneer Settlement in Northeast Argentina. Madison, 1971.

EPSTEIN, D. G.. Brasília, Plan and Reality: A Study of Planned and Spontaneous Urban Development. Berkeley, 1973.

$$
-100-
$$


R. Históris, Sîo Paulo, n. 121, p. 67-110, ago/dez. 1989.

EVENSON, N.. Two Brazilian C'apitals: Architecture and Urbanism in Rio de Janeiro and Brasilia. New Haven, 1973.

FALS BORDA, O.. Indian Congregations in the New Kingdom of Granada. The Americas, v. 13, p. 331-351, 1956-57.

FARRISS, N. M.. Nucleation versus dispersal: the dynamics of population movement in colonial Yucatan., Hispanic American Historical Review, v. 58, p. $187-216,1978$.

FISHBURN, E.. The Portrayal of Immigration in Nineteenth C'entury Argentine Fiction, 1845-1902. Berlin, 1981.

FLORES GALINDO, A.. Arequipa y el Sur Andino, siglos XVIII-XX. Lima: IEP, 1977.

FRANCA, A.. A marcha do café e as frentes pioneras. São Paulo, 1956.

FRANCO, J.. Spanish American Literature. Cambridge, 1969.

FRIEDERICI, G.. Amerikanistischer Worterbuch und Hilfsworterbuch für den Amerikanisten. Hamburg: Cram, de Gruyter, 1960.

GADE, D. W.. The Latin American Central Plaza as a Functional Space. In: R.J. Tata (ed.). Latin America: Search for Geographic Explanations. Boca Raton, p. 16-234, 1974.

GAMBA, V.. The Falklands/Malvinas War: A Model of North-South C'risis Prevention. New York, 1986.

GASPARINI, G.. La casa colonial Venezolana. Caracas, 1962.

GIBSON, C. The Aztecs under Spanish Rule. Stanford: Stanford Univ. Press, 1964.

GILLESPIE, R.. Soldiers of Peron: Argentina's Montoneros. Oxford, 1982.

GÓNGORA, M.. Urban Social Stratification in Colonial Chile. Hispanic American Historical Review, v. 55, p. 421-448, 1975.

GONZÁLEZ, L.. El optimismo nacionalista como factor de la independencia de México. Estudios de Historiografía Americana, v. 12, 1948, p. 143-168.

GONZÁLEZ, M. J.. Plantation Agriculture and Social Control in Northern Peru, 1875-1933. Austin, 1985.

GOODWIN, P. B.. The Central Argentine Railway and the Economic Development of Argentina, 1854-1881. Hispanic American Historical Review, v. 57, p. 626-640, 1977.

GOSSEN, G. H.. Chamulas in the World of the Sun: Time and Space in a Maya Oral Tradition. Cambridge, 1974.

GOTT, R.. Rural Guerrillas in Latin America. London, 1970. 
ROBINSON, David. A linguagem e o significado de lugar na América Latina.

GRAHAM, D. H., BUARQUE DE HOLANDA, S.. Migration, regional and urban growth and the development of Brazil. São Paulo: Instituto de Pesquisas Econômicas, 1971.

GRAVALES G.. Nacionalismo incipiente en los historiadores coloniales. México, 1961.

GUARDA, G.. Historia urbana del reino de Chile. Santiago, 1978.

HAGERMAN JOHNSON, A.. Internal migration in Chile to 1921. Tese de Doutoramento. University of California at Davis, 1978.

HALL, C.. El café y el desarrollo histórico-geográfico de Costa Rica. San José, 1976.

HALL, M. M., SPALDING, H. A.. The urban working class and early Latin American labour movements, 1880-1930. In: L. Bethell (ed.). Cambridge History of Latin America, Cambridge, v. IV, p. 325-366, 1986.

HARDOY, J. E., LANGDON, M. E.. El pensamiento regional en Argentina y Chile entre 1850 y 1930. Mimeo, 1982.

HARRIS, R.. Centralization and decentralization in Latin America. In: G.S. Cheema and D. A. Rondinelli (eds.). Decentralization and Development. Policy Implementation in Developing Countries. Beverly Hills, 1983.

HARRISON, R.. Modes of Discourse: the Relación de Antiguedades deste reyno del Perú, by Joan Salcamaygua. In: R. Adorno (ed.). From Oral to Written Expression: Native Andean C'hronicles of the Early Colonial Period. Syracuse: FACS, 1982.

HAWKINS, J.. Inverse Images: The Meaning of C'ulture, Ethnicity and Family in Postcolonial Guatemala. Albuquerque, 1984.

HERNANDO, D.. Casa y Familia: Spatial Biographies of Nineteenth C'entury Buenos Aires. Tese de Doutoramento, Univ, da California, UCLA, 1973.

HILTON, R. (ed.). The Movement Toward Latin American Unity. New York, 1969.

HIROBAYASHI, L. R.. The migrant village association in Latin America: A comparative analysis. Latin American Research Review. v. 21, p. 7-30, 1986.

HOBERMAN, L. S.. Conclusion. In: L. S. Hobreman and S. M. Socolow (eds.). Cities and Societies in Colonial Latin America. Albuquerque: Univ. of New Mexico Press, 1986.

HOLMER, N. M.. Indian placenames in South America and the Antilles. Names, v. 8, p. 133-149, 1960. 
R. História, São Paulo, n. 121, p. 67-110, ago/dez. 1989.

HOLlOWAY, T.. Immigrants on the land. Coffee and society in São Paulo, 1886-1934. Chapel Hill, 1980.

HOLSTEN, J.. The Modernist City: Architecture, Politics and Society in Brasilia. Tese de Doutoramento, Yale University, 1986.

HUMPHREYS, R. A.. The Caudillo Tradition. In: M. Howard (ed.). Soldiers and Governments. London, p. 149-165, 1957.

HUMPHREYS, R. A.. Tradition and Revolt in latin America. London, 1969.

ISABELL, B. J.. To Defend Ourselves: Ecology and Ritual in an Andean Village. Austin: Texas Univ. Press, 1978.

JOHNSON, J. J.. Latin America in Caricature. Austin, 1980.

JOSEPH, G. M.. Revolution from without: Yucatan Mexico and the United States, 1880-1924. Cambridge, 1982.

JUDGE, J., STANFIELD, J. L.. The Island of Landfall. National Geographic Magazine. v. 170, p. 566-599, 1986.

KARNES, T.L.. The Failure of Union: central America, 1824-1960. Chapel Hill, 1983.

KARRTTUNEN, F.. An Analytical Dictionary of Nahuatl. Austin, 1983.

KATZ, F.. Peasants in the Mexican revlution of 1910. In: J. Spielberg and S. Whiteford (eds.). Forging Nations: A Comparative View of Rural Ferment and Revolt. Lansing, 1976, p. 61-85.

KEMPER, R., Migration and Adaptatin: Tzintzuntzán peasants in Mexico City. Beverly Hills: Sage, 1977.

KICZA, J.. Colonial Entrepreneurs: Families and Business in Bourbon Mexico City. Albuquerque: Univ. of New Mexico Press, 1983.

KLÁREN, P. F.. Modernization, dislocation and Aprismo: origins of the Peruvian Aprista party, 1870-1932, Austin, 1973.

KOHL, J., LITT, J.. Urban Guerrilla Warfare in Latin America. Boston, 1974.

KOROL, J. C., SABATO, H.. The Camps: inmigrantes irlandeses en la provincia de Buenos Aires, 1870-1890. Buenos Aires, 1979.

KOROL, J. C., SABATO, H.. Como fué la inmigración irlandesa en la Argentina. Buenos Aires, 1981.

KUZNESOF, E., OPPENHEIMER, R. (eds.). The Latin American Family in the Nineteenth Century. Special issue on Family History. v. 10, 1985.

LAFAYE, J.. Quetzalcoatl and Guadalupe: The Formation of Mexican National Conciousness, 1531-1815. Chicago, 1976. 
ROBINSON, David. A linguagem e o significado de lugar na América Latina.

LAITE, J.. Industrial development and migrant labor in latin America. Austin, 1981.

LEEDS, A. Locality Power in Relation to Supralocal Power Institutions. In: A. Southall (ed.). Urban Anthropology: C'ross Cultural Studies of Urbanization. New York: Oxford Univ. Press, 1973 p. 15-41.

LEFF, N. H.. Underdevelopment and development in Brazil. London: Allen and Unwin, 1982.

LEFT-PORTILLO, M.. Mesoamerica before 1519. In: L. BETHELL (ed.). Cambridge History of Latin America. Cambridge: Cambridge Univ. Press, v. 1, 1984, p. 3-36.

LEVINE, R. M.. Pernambuco in the Brazilian Federation, 1889-1937. Stanford, 1978.

LIRA, J. A.. Diccionario Kkechuwa-Español. Tucumán: Univ. Nacional de Tucumán, 1944.

LOBO, S.. A House of My Own: Social Organization in the Squatter Settlements of Lima, Peru. Tucson, 1982.

LOCKHART, J.. Capital and Province, Spaniard and Indian: the example of late-sixteenth century Toluca. In: I. Altman and J. Lockhart, (eds.). Provinces of Early mexico. Los Angeles: Univ. da California, 1976.

LOCKHART, J.. Some Nahua Concepts in Postconquest Guise. History of European Ideas, v. 6, p. 465-482, 1985.

LOCKHART, J., SCHWARTZ, S.B.. Early Latin America. Cambridge: Cambridge Univ. Press, 1983.

LÓPEZ-BARALT, M.. La persistencia de las estructuras simbólicas andinas en los dibujos de Guamán Poma de Avala. Jornal of Latin American Lore, v. 5, p. 83-116, 1979.

LOVE, J. L.. São Paulo in the Brazilian Federation, 1889-1937. Stanford, 1980.

LOVELL, W. G.. Conquest and Survival in Colonial Guatemala. Kingston: Queen's McGrill Univ. Press, 1985.

LOWENTHAL, D.. The Past is a Foreign Country. Cambridge, 1985.

LYNCH, J.. The Spanish American Revolutions, 1808-1826. New York: W.W. Norton, 1973.

LYNCH, J.. Argentine Dictator: Juan Manuel de Rosas, 1829-1852. Oxford, 1981.

MAGALLANES, M. V.. Los partidos políticos en la revolución venezolana. Caracas, 1973. 
R. História, São Paulo, n. 121, p. 67-110, ago/clez. 1989.

MALAGA MEDINA, A.. Las reducciones en el virreinato del Peru (1532-1580). Revista de Historia de América, v. 80, p. 9-45, 1975.

MALLON, F. E.. The Defense of C'ommunity in Peru's Central Highlands: Peasant Struggle and Capitalist Transition, 1860-1940. Princeton, 1983.

MAYO, J.. British Merchants and Chilean Development, 1851-1886. Westview: Boulder, 1987.

MAYER, J.. La révolution mexicaine. Paris, 1973.

MEAD, W. R.. The Language of Place. Geographical Studies, v. 1, p. 63-68, 1954.

MONTOYA, R.. Capitalismo y no capitalismo en el Perú: Un estuidio histórico de su articulación en un eje regional. Lima: Mosca Azul, 1981.

MORENO TOSCANO, A.. Toponimia y análisis histórico. Historia Mexicana, v. XIX, p. 1-10, 1969.

MORENO TOSCANO, A. ed.. C'iudad de México: Ensayo de Construcción de una Historia. Mexico: INAH, 1978.

MÖRNER, M.. The Political and Economic Activities of the Jesuits in the La Plata Region. Stockholm, 1953.

MORSE, R. M.. From Community to Metropolis: a Biography of São Paulo. Gainsville, 1958.

MORSE, R. M.. Cities and society in nineteenth century Latin America: the illustrative case of Brazil. In: R. Schaedel et al. (eds.). Urbanization to the present day. The Hague, 1982.

MURRA, J.. Formaciones económicas y políticas del mundo andino. Lima: IEP, 1975.

MURRA, J.. Andean Societies before 1532. In: L. Bethell (ed.). Cambridge History of Latin America. Cambridge: Cambridge Univ. Press, v. 1, 1984, p. 59-90.

NEEDELL, J. D.. Rio de Janeiro at the Turn of the Century: Modernization and the Parisian Ideal , Journal of Interamerican Studies, v. 25, p. 83-103, 1983.

NEWTON, R. C.. German Buenos Aires, 1900-1933: Social Change and C'ultural C'risis. Austin, 1977.

NICHOLS, M.. The Gaucho. New York, 1968.

NUTTALL, Z.. Royal Ordinances Concerning the Laying Out of New Towns. Hispanic American Historical Review. v. 4, p. 743-753, 1921 e v. 5, p. 249-254, 1922. 
ROBINSON, David. A linguagem e o significado de lugar na Annérica Latina.

O'BRIAN, T. F.. The Nitrate Industry and Chile's C'ritical Transition, 1870-1891. New York, 1982.

OLIVER-SMITH, A.. The Martyred C'ity: Death and Rebirth in the Andes. Albuquerque: Univ. of New Mexico Press, 1986.

OSZLAK, O.. The Historical Formation of the State in Latin America: Some theoretical and Methodological Guidelines for its Study. Latin American Research Review, v. 16, p. 3-32, 1981.

PARK, J. W.. Rafael Nuñez and the Politics of Colombian Regionalism, 1863-1886. Baton Rouge, 1985.

PARSONS, J. J.. Antioqueño C'olonization in Western Colombia. Berkeley, 1968.

PEASE, F. (ed.). Nueva C'rónica y Buen Gobierno de Felipe Guamán, Poma de Ayala, Caracas: Biblioteca Ayacucho, 1985.

PEDERSON, N.. Th Mining Industry of the Norte C'hico, C'hile. Evanston, 1966.

PIKE, F.B.. Spanish America, 1900-1970: Tradition and Social Innovation. London, 1973.

PITT-RIVERS, J. A.. The People of the Sierra. Chicago: Univ of Chicago Press, 1961.

PLATT, T.. Symétries en miroir. Le concept de Yanantín chez les Marcha de Bolivies. Annales, E.S.C.. v. 33, p. 1101-1112, 1978.

PORTER, A.. Housing policy urban poverty and the state: the favelas of Rio de Janeiro, 1972-1976. Latin American Research Review, v. 14, p. 3-24, 1979.

RAMOS, D.. Vila Rica: Profile of a Colonial Brazilian Urban Center. The Americas, v. 35, p. 495-526, 1979.

RAMOS MEJÍA, J. M.. Las multitudes argentinas. Buenos Aires, 1899.

RAUSCH, J. M.. A Tropical Plains Frontier: The Llanos of Colombia, 1531-1831. Albuquerque, 1984.

RAYMOND, J.. The Indian Mind in Mexican Toponyms. América Indigena, v. XII, p. 205-216, 1952.

REINA, R.. Paraná: Social Boundaries in an Argentine C'ity. Austin: Univ. of Texas Press, 1973.

RALPH, E. C.. Place and Placelessness. London: Pion, 1976.

REY BALMACEDA, R.. Geografía histórica de la Patagonia. Tese de Doutoramento, Universidade de Buenos Aires, 1961. 
RICARD, R.. La conquête spirituelle du Méxique. Essai sur l'apostolat et les méthodes missionaires des Ordres Mendiants en Nouvelle Espagne, de 1523 a 1572. Paris, 1933.

ROBERTS, B. R.. The interrelationship of city and province in Peru and Guatemala , Latin American Urban Research. v. 4, p. 207-235, 1974.

ROBERTSON, D.. A Belhavioural Portrait of the Mexican Plaza Principal. Tese de Doutoramento, Syracuse University, 1978.

ROBINSON, David J.. Cultural and Historical Perspective in Areas Studies: The Case of Latin America. In: R.U. Cooke and J.H. Johnson (eds.). Trends in Geography. London: Pergamon, 1969.

ROBINSON, David J.. Exploración de oro y su impacto en el panorama cultural de la Guayana venezolana en el siglo XIX. Boletín de la Academia de Ciencias Naturales (Caracas), v. 31, p. 61-111, 1973.

ROBINSON, David J.. The Syndicate System of the Catalan Capuchins of Colonial Southeast Venezuela. Revista de Historia de América, v. 79, p. 63-76, 1975.

ROBINSON, David J.. From Colonial Space to Place. In: D. J. Robinson (ed.), Social Fabric and Spatial Structure in Colonial Latin America. Ann Arbor: Univ. of Michigan Press, 1979, p. 22-24.

ROBINSON, David, J.. Córdoba en 1779: ciudad y campana. Gaea, v. 17, p. 279-312, 1979.

ROBINSON, David J.. La ciudad colonial hispanoamericana: símbolo o texto?. In: José Luis Peset (ed.). Actas del simposio internacional: La ciencia en España e Iberoamérica. Madrid, 1988.

ROBINSON, David J.. (ed.). Population Migration in C'olonial Latin America. Cambridge, 1989.

ROJAS SAMANAZ, A.. Partidos políticos en el Perú. Lima, 1985.

ROSEBERRY, W.. Coffee and C'apitalism in the Venezuelan Andes. Austin, 1983.

RUÍZ, R. E.. Labor and the ambivalent revolutionaries: Mexico 1911-1923. Baltimore, 1976.

SACK, R. D.. Conceptions of Space in Social Thought. London: Macmillan, 1980.

SACK, R. D.. Human Territoriality. Cambridge: Cambridge Univ. Press, 1986.

SANTOS, Milton. Espaço \& método. São Paulo, 1985. 
ROBINSON, David. A linguagem e o significado de lugar na América Latina.

SARGENT, C.. The Spatial Evolution of Greater Buenos Aires, 1870-1930. Tempe, 1974.

SCHMITT, H. C.. The roots of lo Mexicano: self and society in Mexican thought, 1900-1934. College Station, Texas, 1969.

SCHWARTZMAN, S.. Regional cleavages and political patriarchalism in Brazil. Tese de Doutoramento, Universidade da California em Berkeley. 1973.

SCOBIE, J. R.. Revolution on the Pampas: A Social History of Argentine Wheat. Austin, 1964.

SCOBIE, J. R.. Buenos Aires as a Commercial Bureaucratic City, 1880-1910. American Historical Review, v. 77, p. 1035-1073, 1972.

SCOBIE, J. R.. Buenos Aires: from Plaza to Suburb, 1870-1910. New York: Oxford Univ. Press, 1974.

SECKINGER, R.. The Brazilian Monarchy and the South American Republics, 1822-1831: Diplomacy and State Building. Baton Rouge, 1984.

SIMPSON, L. B.. Many Mexicos. Berkeley, 1952.

SLATTA, R. W.. Gauchos and the Vanishing Frontier. Lincoln, 1983.

SOLBERG, C.. Immigration and Nationalism: Argentina and Chile, 1890-1914. Austin, 1970.

SOPHER, E. F.. From Pale to Pampa: The Jewish Immigrant Experience in Buenos Aires. New York, 1980.

SPALDING, H. A.. Education in Argentina, 1890-1914: the limits of oligarchical reform. Journal of Interdisciplinary History, v. 3, p. 41-53, 1972.

SPALDING, K.. Huarochiri: An Andean Society under Inca and Spanish Rule. Stanford: Stanford Univ. Press, 1984.

SPECKER, J.. Die Missionmethode in Spanisch-Amerika im I6 Jahrhundert. Cologne: Schoneck-Beckenried, 1953.

STABB, M. S.. In Quest of Identity: Paterns in the Spanish American Essay of Ideas, 1890-1960. Chapel Hill, 1967.

STERN, S.. Peru's Indian Peoples and the Challenge of Spanish Conquest: Huamanga to 1640. Madison: Univ. of Wisconsin Press, 1982.

SZUCHMAN, M.. The Limits of the Melting Pot in Córdoba, 1869-1909. Hispanic American Historical Review, v. 57, p. 24-50, 1977.

SZUCHMAN, M.. Mobility and Integration in Urhan Argentina: Cordoba in the Liberal Era. Austin, 1980. 
R. Hilistórk, Sẫo Paulo, n. 12.1, p. 67-110, ago/dez. 1989.

TAKAGI, H.. The Plaza and its functions in a Mexican highland community: Tepeojuma. Geographical Review of Japan, v. 43, p. 22-31, 1970.

THORNDIKE, G.. Uchuraccay: testimonia de una masacre. Lima, 1983.

TODOROV, T.. The Conquest of America: The Question of the Other. New York, 1982.

TORRE REVELLO, J.. La casa y el mobilario en Buenos Aires colonial. Revista de la Universidad de Buenos Aires, v. 3, p. 285-300, 1945.

TUAN, Yi Fu. Topophilia. Nova Iorque: Prentice Hall, 1974.

TUAN, Yi Fu. Place: An Experimental Perspective. Geographical Review, v. 65, p. 151-156, 1975.

TUAN, Yi Fu. Space and Place: The Perspective of Experience. Minneapolis, 1977.

TUAN, Yi Fu. In Place, Out of Place. Geoscience and Man, v. 24, p. 3-10, 1984.

UZZELL, D.. The interaction of population and locality in the development of squatter settlements in Lima. Latin American Urban Research, v. 4, p. 113-134, 1974.

VAYSSIèRE, P.. Un siècle de capitalisme minier au Chile, 1830-1930. Paris, 1980.

VANDEN, H. E.. Mariátegui: Marxismo, Comunismo, and Other Bibiographical Notes. Latin American Research Review, v. 14, p. 61-86, 1979.

VIAL CORREA, G.. La formación de nacionalidades hispano-americanas como causa de la independencia. Boletín de la Academia C'hilena de Historia, v. 333,1966 , p. $110-144$.

WACHTEL, N.. Pensée sauvage et acculturation. L'espace et le temps chez Felipe Guamán Poma de Ayala. Annales. E.S.C, v. 41, p. 793-840, 1971.

WASSERMAN, M.. C'apitalists, caciques and revolution: elite and foreign enterprise in Chihuahua, 1854-1911. Chapel Hill, 1984.

WEIBEL, L.. Place names as an aid to the reconstruction of the original vegetation of Cuba. Geographical Review, v. 33, p . 376-396, 1948.

WEINSTEIN, B.. Brazilian regionalism. Latin American Research Review, v. 17, p. 262-276, 1982.

WEINSTEIN, B.. The Amazon Rubber Boom, 1850-1920. Stanford, 1983.

WHITE, S.. Movements in the Cultural Landscape of Highland Peru. Tese de Doutoramento, University of Wisconsin. Madison, 1981.

$$
-109-
$$


ROBINSON, David. A linguagem e o significado de lugar na América Latina.

WHITEHEAD, L.. National power and local power: the case of Santa Cruz de la Sierra, Bolivia., Latin America Urban Research, v. 3, p. 23-48, 1973.

WHITEFORD, S.. Workeds from the North: Plantations, Bolivian labor and the City in Northwest Argentina. Austin, 1981.

WILLIAMS, R. Bryn. Y Wladfa. Cardiff, 1964.

WILLIAMS, R. Bryn. The structure and process of Welsh emigration to Patagonia. Welsh History Review, v. 8, p. 42-74, 1976.

WIRTH, J. D.. Minas Gerais in the Brazilian Federation, 1889-1937. Stanford, 1977.

WOLL, A.. A functional past. The uses of history in nineteeth century Chile. Baton Rouge, 1982.

WOMACK, J.. Zapata and the Mexican Revolution. New York, 1969.

WORTMAN, M.. Legitimidad política y regionalismo. El imperio Mexicano y Centroamerica. Historia Mexicana, v. 26, p. 238-262, 1976.

ZUIDEMA, R. T.. The ceque System of Cusco: The Social Organization of the C'apital of the Incas. Leiden: E. J. Brill, 1964.

ABSTRACT: The article analyses the cultural meaning of the concepts of space and locality and their diversification throughout Latin American history. For the incas and the aztecs, places had a kin conotation of social relations between relatives. In the andean societies, both superior and inferiors parts of their geographic setting indicated complementary activities (p. 78). Local chapels (capellas) were santuaries for harvest and fertility rites. After the Spanish conquest, localities involved a whole network of hierarquic and power relations as between social, national and imperial. During the process of construction of the state local, federative, central and national came to have opposite meanings. Later on, they were substituted for notions like peripheric and metropolitan. Post modern connotations point to new forms of localities and resistance towards burocratic planning. A new and insolite geography responds to touristical organizations (p. 99). 